Article

\title{
Condensate-Banking Removal and Gas-Production Enhancement Using Thermochemical Injection: A Field-Scale Simulation
}

\author{
Amjed Hassan ${ }^{1}$, Mohamed Abdalla ${ }^{1}$, Mohamed Mahmoud ${ }^{1}$, Guenther Glatz ${ }^{1, *}$ (1), \\ Abdulaziz Al-Majed ${ }^{1}$ and Ayman Al-Nakhli ${ }^{2}$ (D) \\ 1 College of Petroleum Engineering and Geosciences, King Fahd University of Petroleum and Minerals, \\ Dhahran 31261, Saudi Arabia; g201205100@kfupm.edu.sa (A.H.); mohamed.abdalla@kfupm.edu.sa (M.A.); \\ mmahmoud@kfupm.edu.sa (M.M.); aamajed@kfupm.edu.sa (A.A.-M.) \\ 2 Advanced Research Center (EXPEC ARC), Dhahran 31311, Saudi Arabia; ayman.nakhli@aramco.com \\ * Correspondence: guenther@kfupm.edu.sa
}

Received: 10 May 2020; Accepted: 20 June 2020; Published: 23 June 2020

\begin{abstract}
Condensate-liquid accumulation in the vicinity of a well is known to curtail gas production up to $80 \%$. Numerous approaches are employed to mitigate condensate banking and improve gas productivity. In this work, a field-scale simulation is presented for condensate damage removal in tight reservoirs using a thermochemical treatment strategy where heat and pressure are generated in situ. The impact of thermochemical injection on the gas recovery is also elucidated. A compositional simulator was utilized to assess the effectiveness of the suggested treatment on reducing the condensate damage and, thereby, improve the gas recovery. Compared to the base case, represented by an industry-standard gas injection strategy, simulation studies suggest a significantly improved hydrocarbon recovery performance upon thermochemical treatment of the near-wellbore zone. For the scenarios investigated, the application of thermochemicals allowed for an extension of the production plateau from 104 days, as determined for the reference gas injection case, to 683 days. This represents a 6.5 -fold increase in production plateau time, boosting gas recovery from 25 to $89 \%$. The improved recovery is attributed to the reduction of both capillary pressure and condensate viscosity. The presented work is crucial for designing and implementing thermochemical treatments in tight-gas reservoirs.
\end{abstract}

Keywords: tight reservoirs; gas recovery; thermochemical treatment; field-scale simulation

\section{Introduction}

Condensate banking constitutes a common challenge for hydrocarbon production from tight-gas reservoirs [1-3]. The reduction of reservoir pressure below dew point gives rise to condensate dropout [4-6]. Liquid accumulates near the wellbore, potentially reducing gas production by up to $80 \%[2,7,8]$. Several methods are employed to remove condensate damage and restore gas productivity $[3,9]$. Gas injection and hydraulic fracturing are among the most effective treatments in mitigating condensate banking [10-12].

Generally, gas injection aims to either increase or maintain pressure in proximity of the wellbore above dew-point pressure $[10,13,14]$, allowing for the revaporization of the condensate liquid into the gas phase $[4,15,16]$. Usually, gas injection is initiated every six to nine months depending on specific reservoir conditions [3,9]. Treatment involves the injection of hydrocarbon gases like methane, or nonhydrocarbon gases like nitrogen or carbon dioxide, in combination with a cyclic intervention approach $[10,12,16-18]$. The administration of carbon dioxide in a huff-and-puff configuration in particular shows great potential in mitigating condensate banking owing to the ability of $\mathrm{CO}_{2}$ gas to reduce the dew-point pressure of condensates, hence counteracting liquid dropout $[12,19,20]$. Notably, 
though, this procedure needs to be repeated about every 6 to 9 months to maintain its effectiveness, giving rise to logistical challenges associated with $\mathrm{CO}_{2}$ procurement, transportation, and on-site handling challenging its economic viability $[3,9,21]$.

Alternatively, hydraulic fracturing may be used to mitigate condensate banking by creating longer conductive paths between wellbore and formation $[9,11,22]$. Fractures induce help to reduce pressure drop, and delay condensate dropout [11,23]. However, once reservoir pressure drops below dew point as a result of the ongoing depletion process, liquids precipitate and accumulate within fractures, and then impede gas flow towards the production well [3,9]. Solvent or gas injection may be used to vaporize the liquids and re-establish fracture conductivity $[11,23]$.

Evidently, gas injection, hydraulic fracturing, or a combination thereof constitute pragmatic approaches to mitigating condensate banking. However, gas injection needs to be executed on a frequent basis to maintain its efficacy. Hydraulic fracturing only delays the inevitable development of a condensate bank. Hence, at some point, gas injection may be required to become part of the reservoir-management process. Needless to say, both gas-injection and hydraulic-fracturing treatments are of great concern with respect to project economics [3,9]. Therefore, in this paper, an innovative condensate-treatment concept based on thermochemical fluids (TCFs) is introduced [3,24-27]. Exploiting enthalpy associated with the thermochemical reaction allows for remarkable increases in pressure and temperature to be realized downhole [28,29]. The suggested treatment exhibits an attractive performance profile that can combat condensate-banking-related challenges for various types of gas reservoirs associated with carbonate, sandstone, and shale formations [27,30].

Figure 1 illustrates the concept of thermochemical injection for removing the condensate bank. Initially, during gas production, condensate liquid drops out and accumulates in the vicinity of the wellbore, thereby restricting gas flow towards the producing well. The injection of TCFs into the condensate-banking zone helps to reduce fluid viscosity and improve condensate mobility. Furthermore, in situ generated pressure and temperature increase associated with the thermochemical reaction provide additional driving force, enhancing the flow of the condensate liquid into the well. Several fluids, such as magnesium sulfate, sodium nitrate, and ammonium chloride solutions, may be used. Importantly, compared to conventional methods, the outlined process yielded higher thermal efficiency and lower energy loss compared to those of conventional gas-injection methods on an equimolar basis.

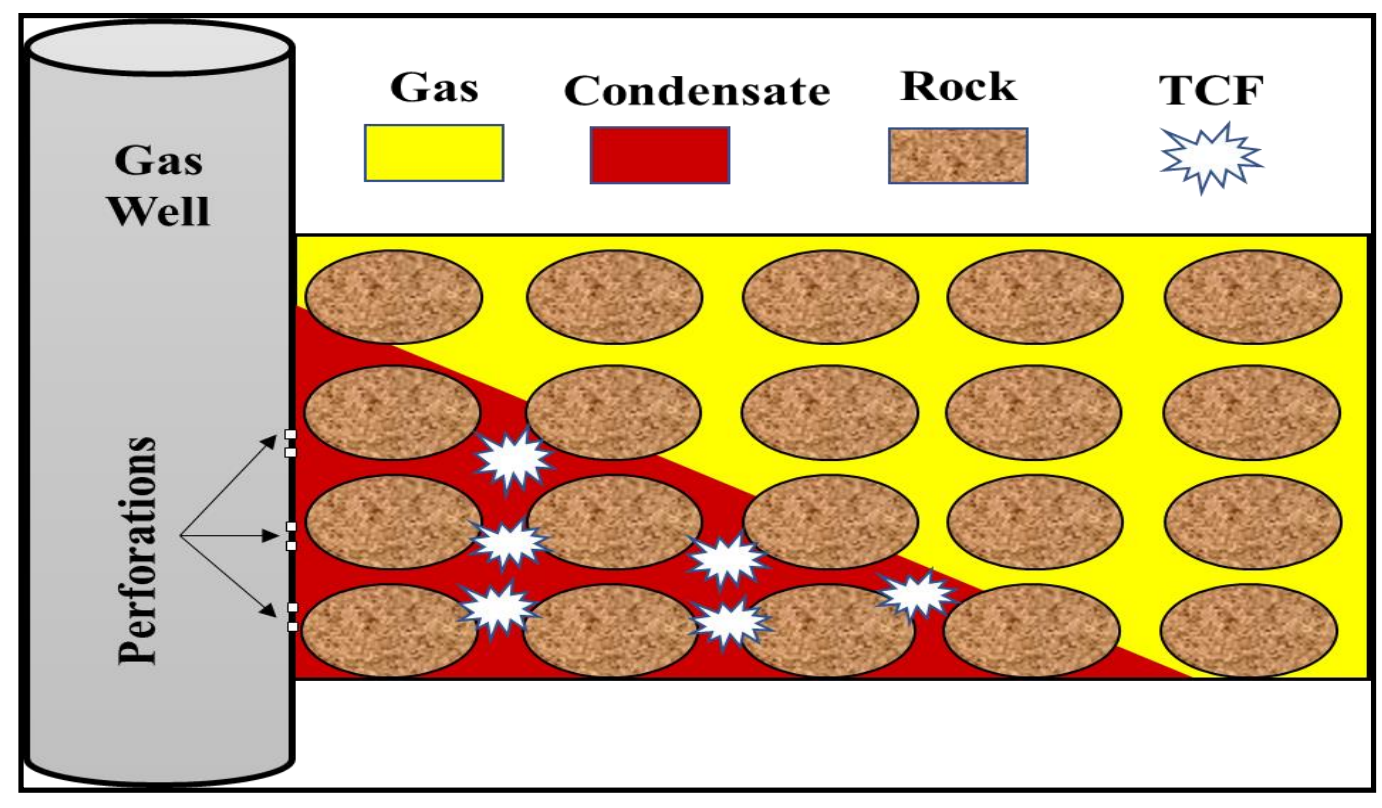

Figure 1. Proposed and experimentally proven technique for condensate-bank removal using thermochemical injection. 
Given successful lab trials [24-27,30], this paper for the first time presents a field-scale simulation based on experimentally obtained data for condensate removal from gas reservoirs by means of a thermochemical treatment strategy. In addition, sensitivity analysis was conducted to study the impact of different wellbore conditions on gas-production rate. Furthermore, the relationship between condensate-bank development, and gas-production rate and flowing bottom-hole pressure was investigated. Lastly, the effectiveness of thermochemical treatments reflected in associated production profiles was contrasted with a conventional gas-injection approach.

\section{Methodology}

\subsection{Process Description}

The described thermochemical process constitutes the injection of two chemicals that mutually react under downhole conditions to generate heat and nitrogen, thereby significantly increasing pressure and temperature. The induced temperatures and pressures can yield changes in the excess of $533 \mathrm{~K}\left(500^{\circ} \mathrm{F}\right)$ and $35 \mathrm{MPa}(5000 \mathrm{psi})$, respectively, depending on injected TCF volume and chemical concentrations. In this work, two aqueous solutions (sodium nitrite $\mathrm{NaNO}_{2}$ and ammonium chloride $\mathrm{NH}_{4} \mathrm{Cl}$ ) were used as thermochemical fluids. The thermochemical reaction is given by the following equation [24,29]:

$$
\mathrm{NH}_{4} \mathrm{Cl}+\mathrm{NaNO}_{2} \rightarrow \mathrm{NaCl}+2 \mathrm{H}_{2} \mathrm{O}+\mathrm{N}_{2}+\Delta \mathrm{H} \text { (heat) }
$$

The reaction could be accelerated by increasing temperature and/or lowering system $\mathrm{pH}$ below 4 . During the reaction, the produced nitrogen gas $\left(\mathrm{N}_{2}\right)$ led to a rise in pressure, and generated heat $(\Delta \mathrm{H})$ resulted in an increase in temperature. Consequently, TCF injection into a condensate region supported the revaporization of a portion of the condensate liquid, and the reduction of both condensate viscosity and density. Furthermore, in field applications, the chemical reaction could be triggered inside the reservoir formations to minimize risks associated with chemical reaction. Thermochemical fluids can be injected into the formation around the wellbore; then, acidic fluid is injected to lower $\mathrm{pH}$, it can activate exothermic reactions within the reservoir formation.

During the experiment investigation, heat and pressure were monitored, and condensate properties were measured before and after introducing TCFs. Figure 2 displays the experiment configuration used to monitor the process. The setup consisted of a high-pressure and high-temperature (HPHT) reactor, pressure and temperature sensors, a heater, an $\mathrm{N}_{2}$ cylinder, and a data-acquisition system. Thermochemical fluids were injected into the HPHT reactor, and no rock sample was used in order to minimize the uncertainty associated with rock composition. Subsequently, the reaction was triggered by acetic acid. A pressure source $\left(\mathrm{N}_{2}\right.$ cylinder) was utilized to study the reaction behavior for various pressures. High-accuracy sensors in combination with a data logging system were used to record the temperature and pressure profiles as a function of time.

Figure 3 summarizes the recorded temperature profiles resulting from the reaction at different initial system temperatures of $292,314,328$, and $347 \mathrm{~K}\left(65,105,130\right.$, and $\left.165^{\circ} \mathrm{F}\right)$. For all temperatures, the reaction increased the in situ temperature by around $333.15 \mathrm{~K}\left(140^{\circ} \mathrm{F}\right)$. Expectedly, for higher initial temperatures, temperature peaks were reached more quickly compared to lower initial-temperature conditions. The conversion of reactants as a function of time for various initial temperatures is plotted in Figure 4. The time to reach the peak temperature decreased from $1000 \mathrm{~s}$, for an initial temperature of $292 \mathrm{~K}\left(65^{\circ} \mathrm{F}\right)$, to around $320 \mathrm{~s}$, for an operating temperature of about $347 \mathrm{~K}\left(165^{\circ} \mathrm{F}\right)$. 


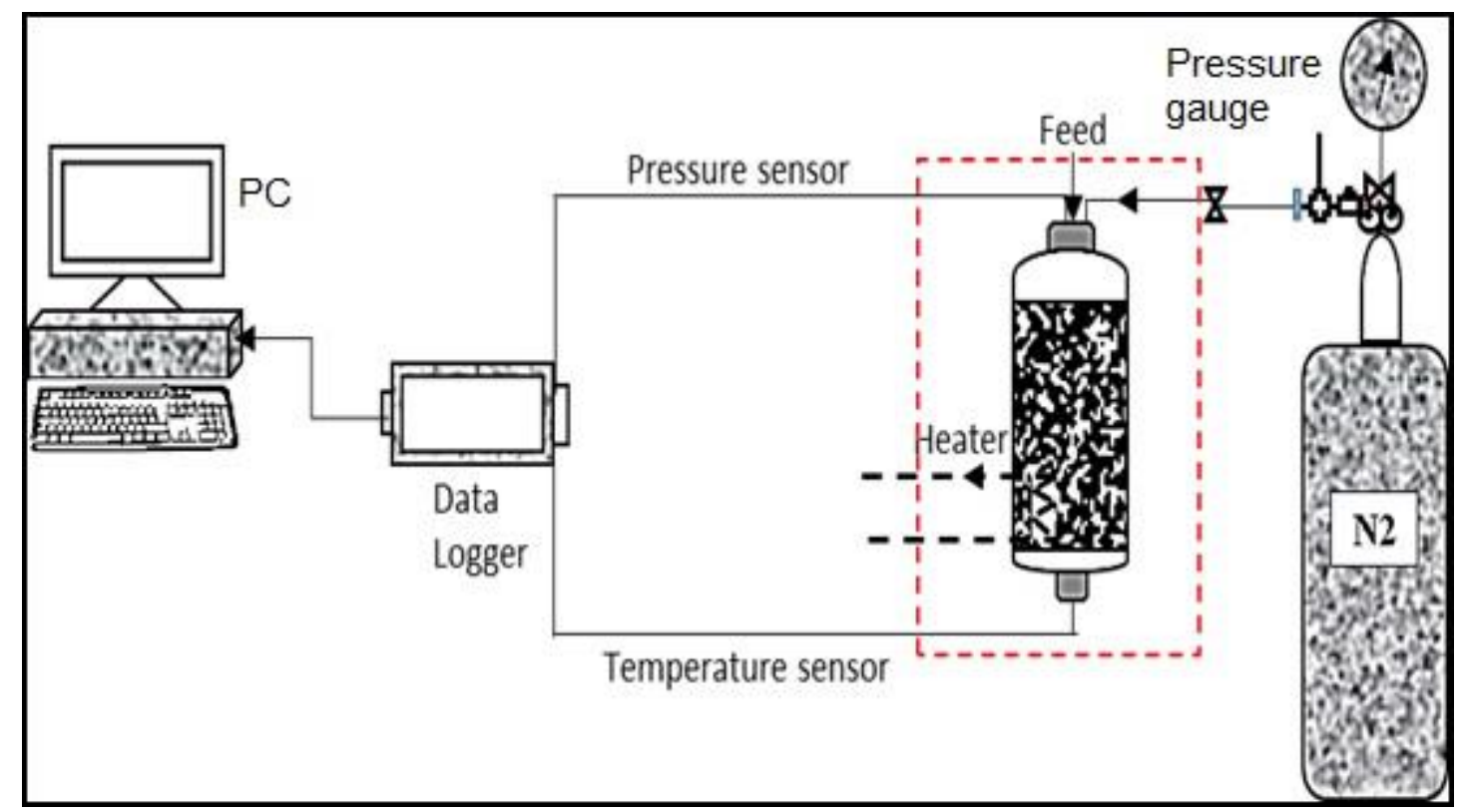

Figure 2. Experiment setup for monitoring thermochemical process.

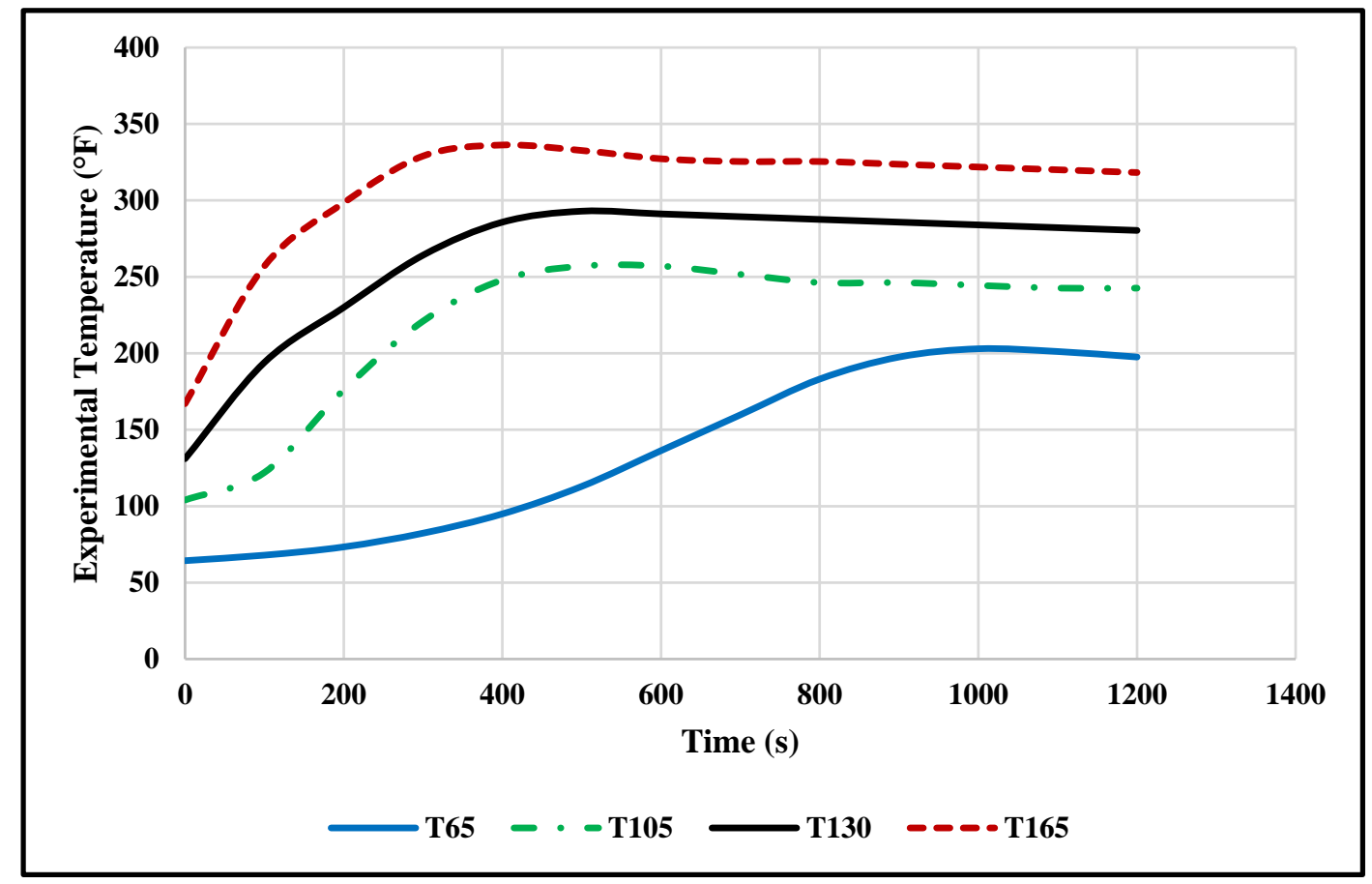

Figure 3. Temperature profiles for different initial vessel temperatures.

In addition, enthalpy impact on condensate liquids was investigated. Figures 5 and 6 illustrate the temperature and pressure profiles for two selected cases, only TCFs and a thermochemical-condensate system. Higher temperatures were recorded for the pure TCF system, while introducing the condensate liquid into the TCF system led to a reduction of the temperature, measured by around $7.4 \mathrm{~K}\left(11^{\circ} \mathrm{F}\right)$ due to the added thermal capacity of the condensate. The condensate properties were changed considerably after the chemical reaction occurred. Rheological measurements substantiated condensate-viscosity reduction from 0.94 to $0.57 \mathrm{cP}$ after TCF injection, amounting to a $39 \%$ decrease. Upon injection, generated pressure increased the gradient to push the condensate liquid towards the producing well. Importantly, the pressure generated multiple fractures (Figure 7) in the treated formations, 
thereby increasing pore-throat size and reducing capillary pressure by up to $51 \%$ [25]. The reduction in capillary pressure due to the creation of multiple fractures can be explained by the following equation [25,31]:

$$
P_{c}=\frac{2 \sigma \cos \theta}{r}
$$

where $P_{c}$ is capillary pressure, $\sigma$ is interfacial tension, $\theta$ is contact angle, and $r$ is pore-throat size.

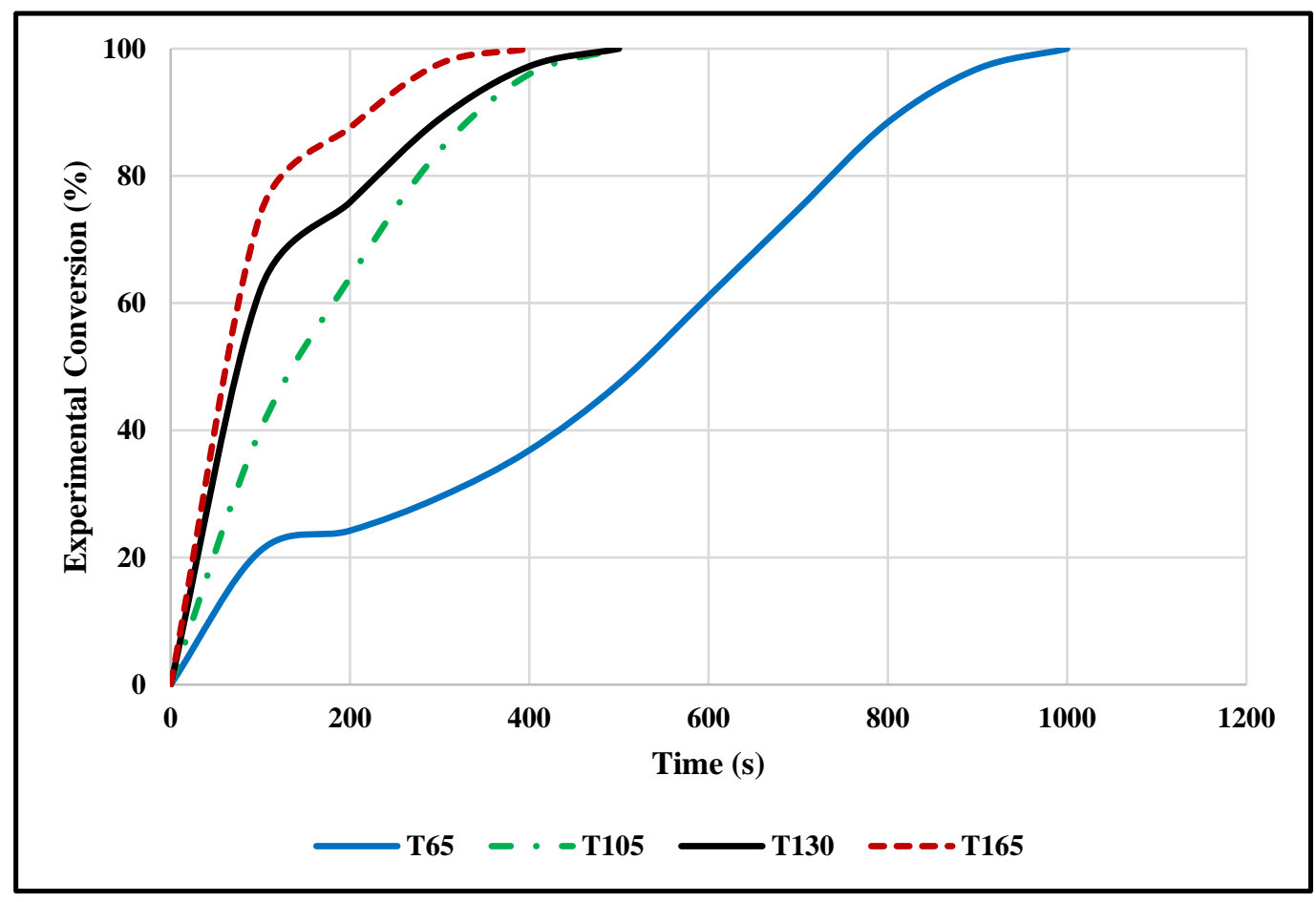

Figure 4. Conversion profiles for different initial vessel temperatures.

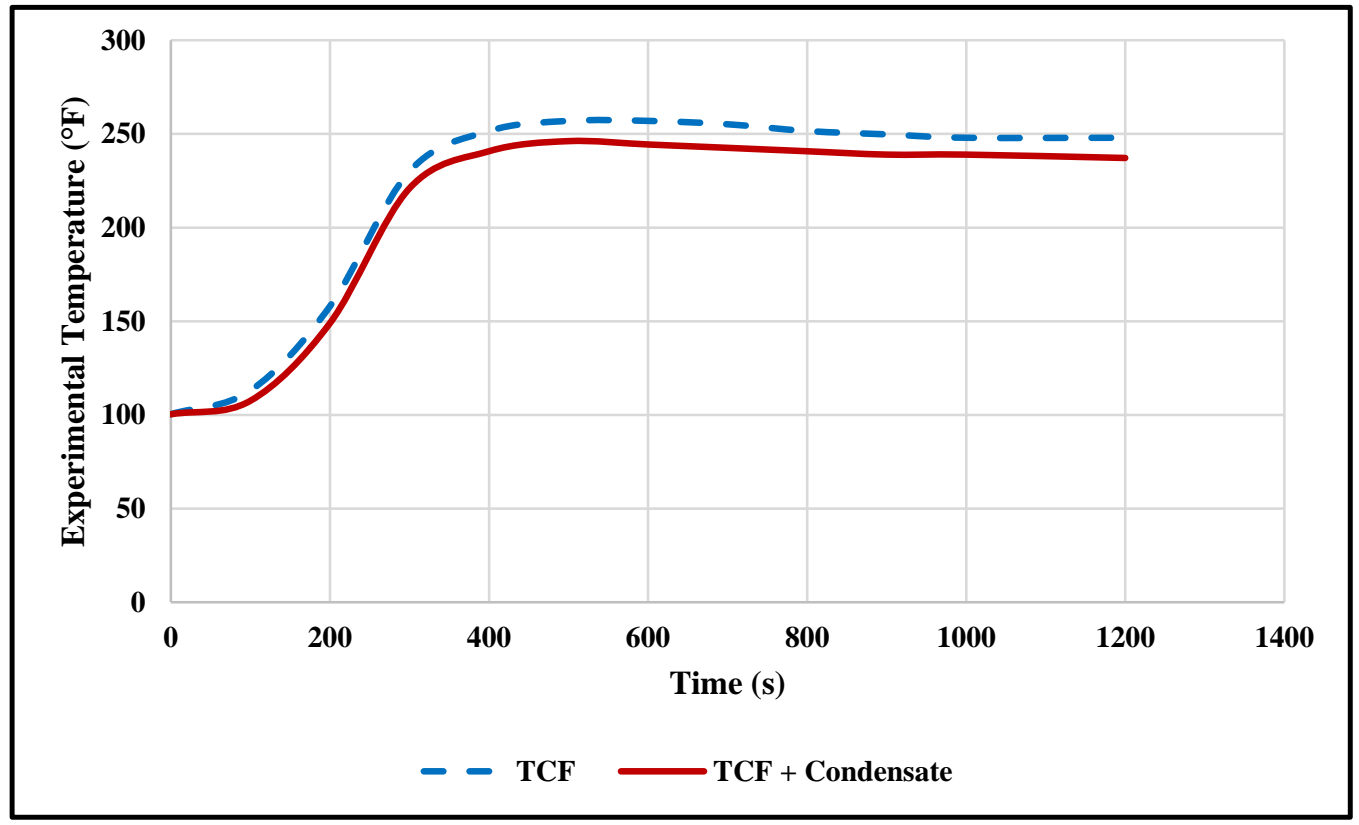

Figure 5. Temperature profiles for pure thermochemical-fluid (TCF) and TCF-condensate system. 


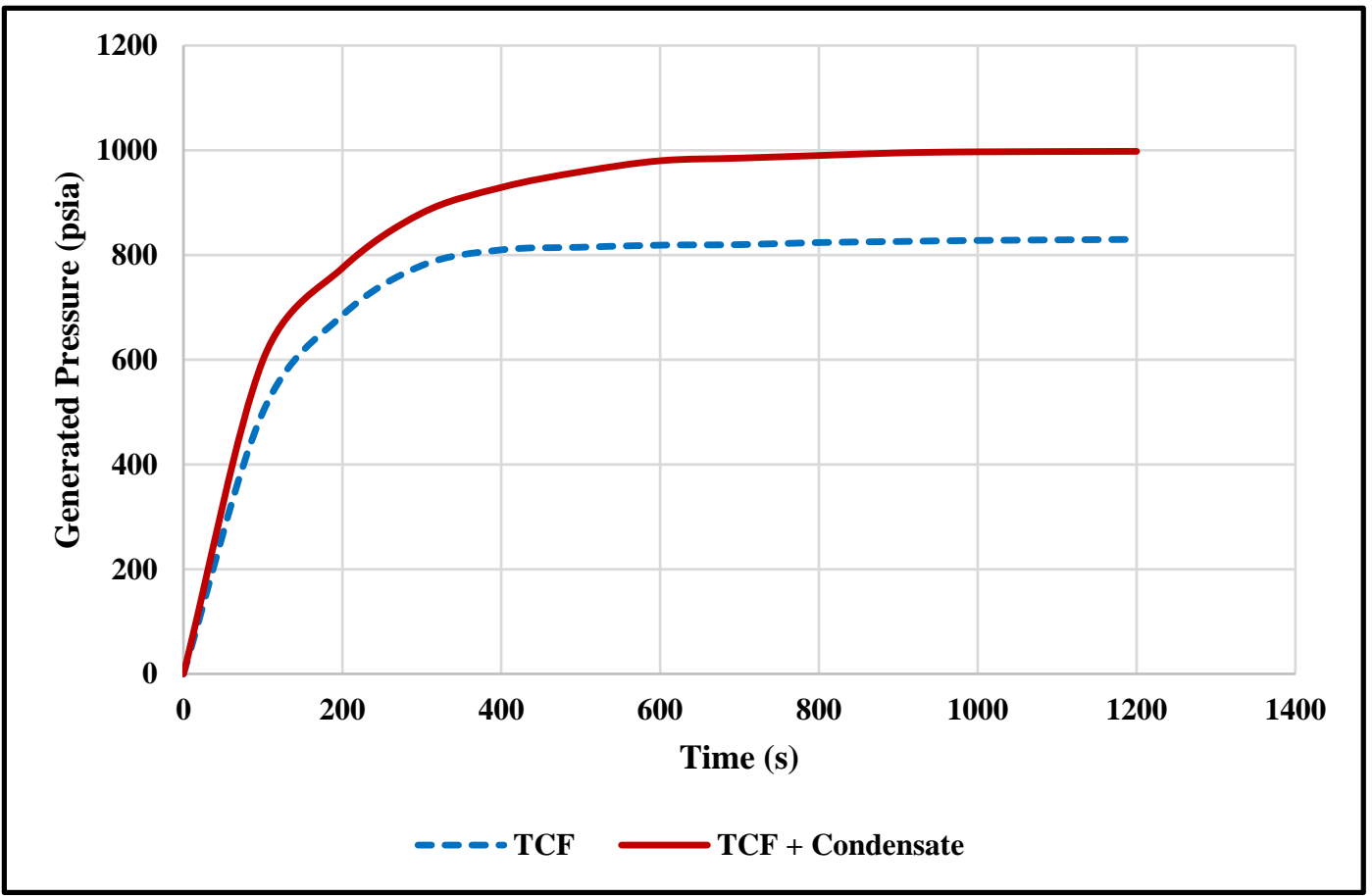

Figure 6. Pressure profiles for a pure thermochemical fluid (TCF) and TCF-condensate system.

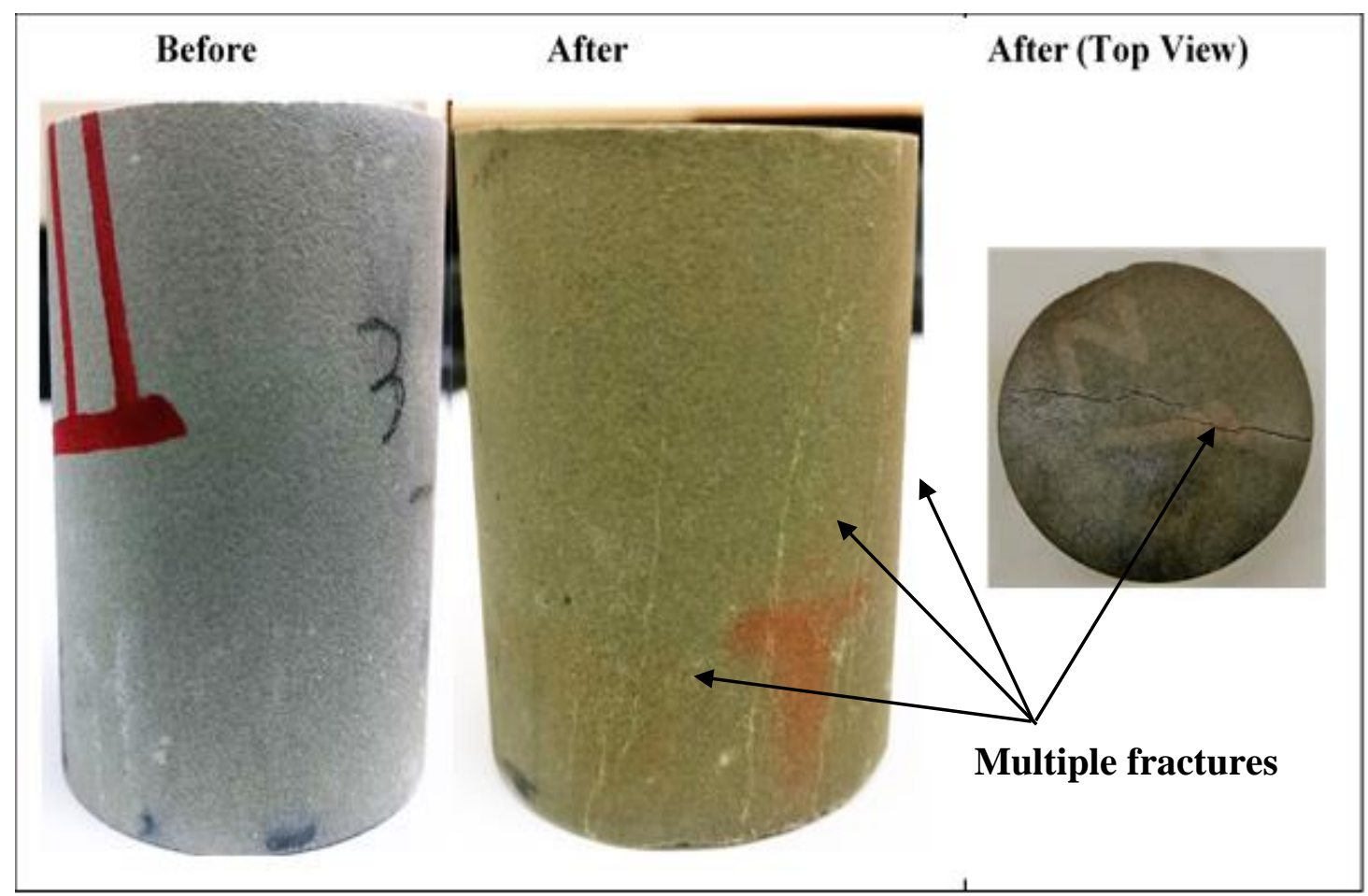

Figure 7. Images of rock sample before and after thermochemical injection. Multiple fractures induced upon thermochemical treatment [25].

\subsection{Reservoir Model}

An advanced equation-of-state (EoS) compositional and unconventional simulator (GEM) from Computer Modelling Group (CMG) software was utilized. The used data were collected from the available literature [32-34]. Ayub and Ramadan [12] examined reservoirs with respect to the areal extensions and associated drainage areas in the vicinity of the gas-production well. They reported 
that a 1 by $1 \mathrm{~km}$ sector could accurately represent the actual behavior of pressure depletion for a gas-condensate reservoir. Consequently, the reservoir was built around a Cartesian grid covering a square area of $1 \mathrm{~km}^{2}$. Figure 8 provides an overview of the reservoir model used in this work. The initial reservoir conditions are listed in Table 1. Vertical heterogeneity is captured by defining four layers with permeabilities ranging from 5 to $315 \mathrm{mD}$. On the basis of field data reported by Whitson and Kuntadi [34], reservoir porosity was given with 0.13 , initial reservoir pressure with $48.3 \mathrm{MPa}(7000 \mathrm{psi})$, temperature with $408 \mathrm{~K}\left(275^{\circ} \mathrm{F}\right)$, and rock compressibility with $3.5 \mathrm{e}-8$ 1/Mpa (5.0e-6 1/psia). A single well was completed in the model center, and production simulated for a total of five years. Two wellbore constraints were applied with minimal flowing bottom-hole pressure of 10.4 MPa (1500 psi) and maximal flow rate of 30 MMSCFD.

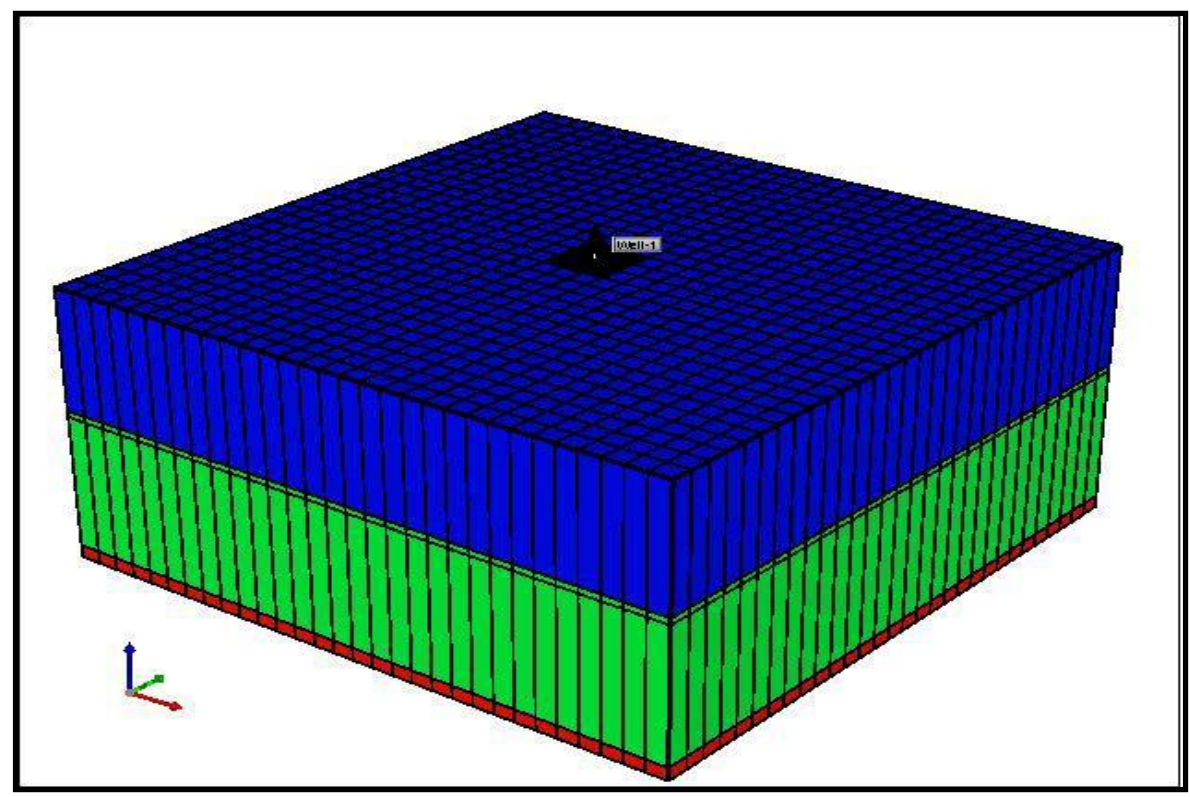

Figure 8. Three-dimensional view of rectangular reservoir model used in simulation.

Table 1. Initial reservoir conditions.

\begin{tabular}{cc}
\hline Parameter & Value \\
\hline Total bulk reservoir volume $\left(\mathrm{ft}^{3}\right)$ & $9.00 \times 10^{8}$ \\
\hline Total pore volume $\left(\mathrm{ft}^{3}\right)$ & $1.17 \times 10^{8}$ \\
\hline Total hydrocarbon pore volume $\left(\mathrm{ft}^{3}\right)$ & $9.83 \times 10^{7}$ \\
\hline Original oil in place, OOIP $(\mathrm{STB})$ & $1.79 \times 10^{6}$ \\
\hline Original gas in place, OGIP $(\mathrm{SCF})$ & $2.77 \times 10^{10}$ \\
\hline
\end{tabular}

In addition, relative-permeability curves were generated using available correlations in CMG software based on Corey's model [35]. Figures 9 and 10 summarize the relative-permeability curves used in this work, respectively. 


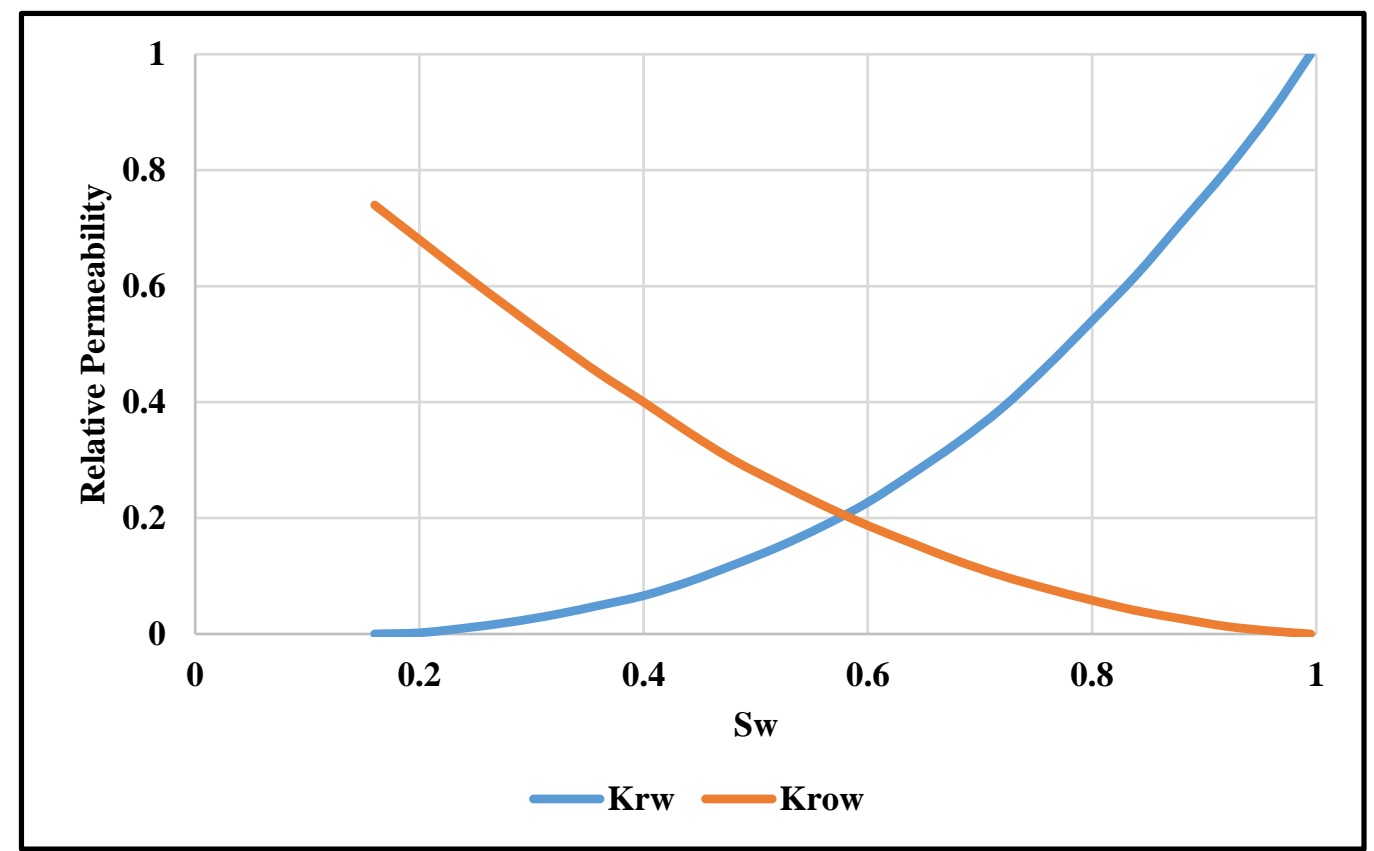

Figure 9. Water $\left(\mathrm{K}_{\mathrm{rw}}\right)$ and oil $\left(\mathrm{K}_{\text {row }}\right)$ relative-permeability curves used in simulation model.

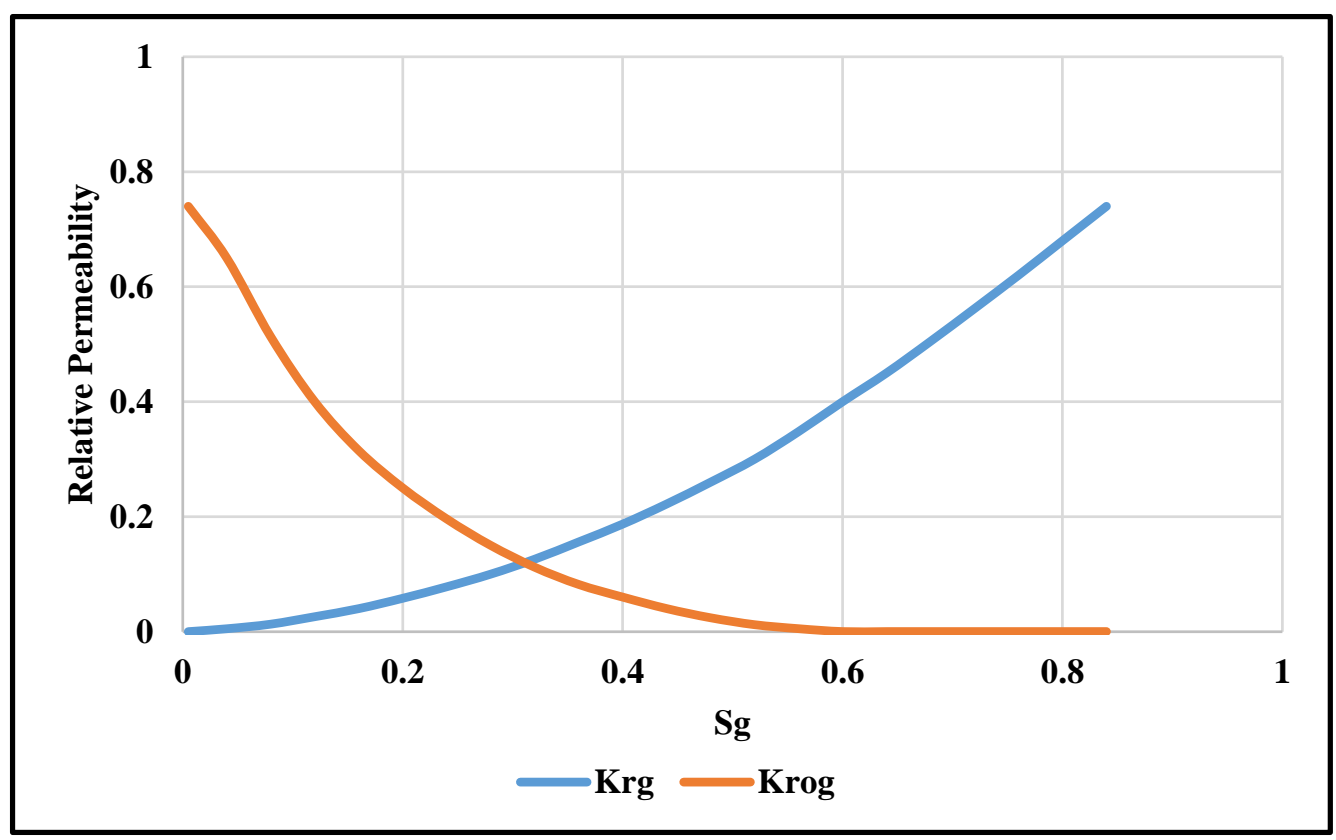

Figure 10. Gas $\left(\mathrm{K}_{\mathrm{rg}}\right)$ and oil $\left(\mathrm{K}_{\mathrm{rog}}\right)$ relative-permeability curves used in this study.

\subsection{Fluid Model}

The fluid-property-characterization tool (WinProp) was employed to develop the EoS model on the basis of the Peng-Robinson framework using the fluid composition listed in Table 2. Figure 11 details the resulting two-phase envelope. During production, reservoir pressure decreased entering the two-phase region, allowing for gas and liquid condensate to coexist. Generally, it can be assumed that the gas is produced under isothermal conditions. Heat loss from the reservoir was considered negligible due to the poor thermal conductivity of the reservoir rock and the insulating nature of the overburden formations. Importantly, constant composition expansion (CCE) measurements were used to validate the developed fluid model. An acceptable match was achieved between experiment measurements and simulation results, as evidenced in Figure 12. 
Table 2. Fluid composition adopted in this work [32-34].

\begin{tabular}{cc}
\hline Component & Mol \% \\
\hline $\mathrm{N}_{2}$ & 10.07 \\
\hline $\mathrm{CO}_{2}$ & 2.01 \\
\hline $\mathrm{H}_{2} \mathrm{~S}$ & 2.65 \\
\hline $\mathrm{CH}_{4}$ & 66.89 \\
\hline $\mathrm{C}_{2} \mathrm{H}_{6}$ & 6.85 \\
\hline $\mathrm{C}_{3} \mathrm{H}_{8}$ & 3.05 \\
\hline $\mathrm{NC}_{4}$ & 1.25 \\
\hline $\mathrm{IC}_{4}$ & 0.59 \\
\hline $\mathrm{NC}_{5}$ & 0.5 \\
\hline $\mathrm{IC}_{5}$ & 0.46 \\
\hline $\mathrm{FC}_{6}$ & 0.68 \\
\hline $\mathrm{FC}_{7}$ & 0.79 \\
\hline $\mathrm{FC}_{8}$ & 0.8 \\
\hline $\mathrm{FC}_{9}$ & 0.67 \\
\hline $\mathrm{FC}_{10}$ & 0.53 \\
\hline $\mathrm{FC}_{11}$ & 0.33 \\
\hline $\mathrm{C}_{12+}$ & 1.88 \\
\hline $\mathrm{Sum}$ & $\mathbf{1 0 0 . 0 0}$ \\
\hline
\end{tabular}

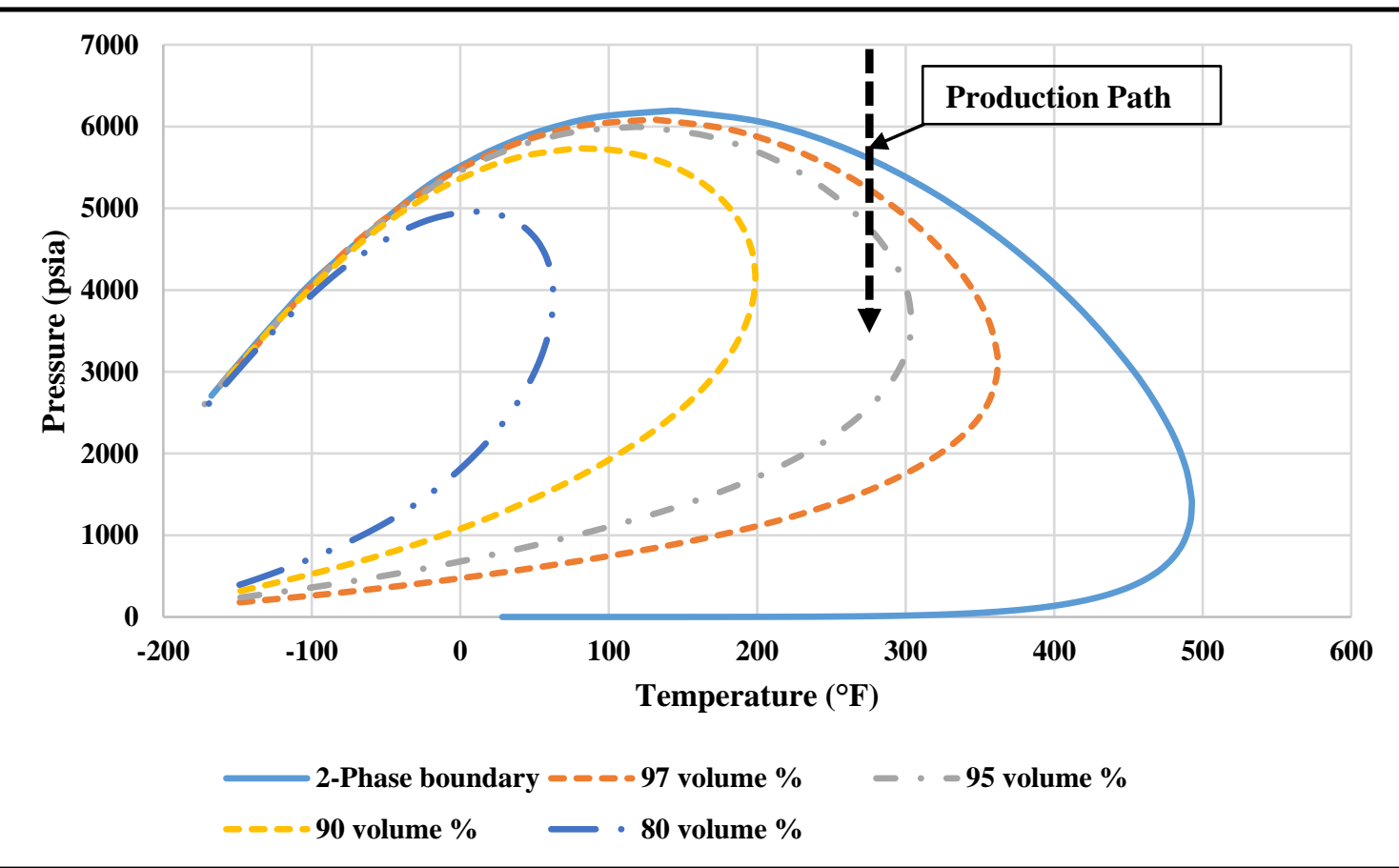

Figure 11. Two-phase diagram for the gas condensate reservoir under consideration. The straight line indicates the assumed isothermal pressure depletion program. 


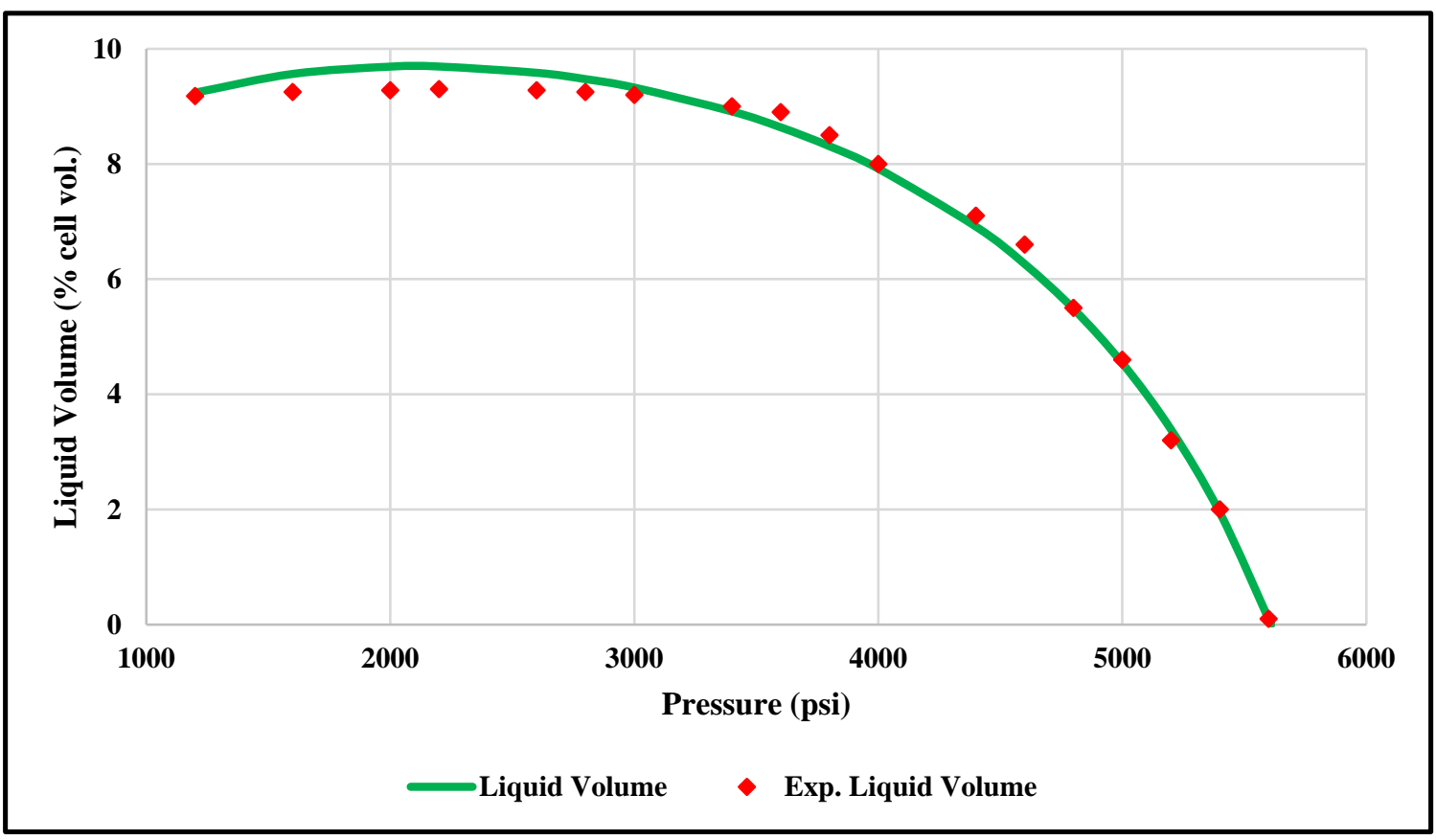

Figure 12. Simulation results and experiment measurements for constant-composition expansion.

\section{Results and Discussion}

The simulation work was conducted in two stages: condensate development and thermochemical injection. First, the impact of wellbore conditions on condensate formation was studied. The effects of flowing bottom-hole pressure and gas-production rate on the development of condensate banking were examined. A sharp decrease in the gas-production profile served as an indicator for condensate banking. Next, production plateau time, defined as the duration of stabilized gas production, was calculated as functions of both gas-flow rate and flowing bottom-hole pressure. During the second stage, the thermochemical treatment was initiated. The effects of in situ generated heat, and pressure triggered by the thermochemical reaction on condensate bank and gas production were studied. Lastly, the effectiveness of the thermochemical treatment was compared with the efficiency of the conventional gas-injection approach in terms of stabilized production times and total gas recovery.

\subsection{Impact of Flowing Bottom-Hole Pressure}

The relationship between the evolution of the condensate bank and associated flowing bottom-hole pressure was studied by producing the hydrocarbon gas at different levels of flowing bottom-hole pressure (BHP). Figure 13 summarizes the profiles of gas-flow rates at flowing bottom-hole pressure of 3.5, 6.9, and 10.4 MPa (500, 1000, and $1500 \mathrm{psi})$, respectively. Production was constrained to a maximal gas-flow rate of $30 \mathrm{MMSCFD}$. Initially, the well produced at a constant production rate with bottom-hole pressure decreasing as a result of the depletion process. Once pressure reached a specified BHP value (500, 1000, and $1500 \mathrm{psi})$, it was kept constant, and production rate correspondingly decreased until it reached 0 MMSCFD, revealing that the well had been killed due to condensate banking. At this point, the relationship between stabilized gas-production rate and flowing bottom-hole pressure was determined. Figure 14 plots the production plateau as a function of flowing bottom-hole pressure. Evidently, a decrease in flowing bottom-hole pressure allowed for sustaining the production plateau for increased periods of time. For example, the production plateau could be increased by around $13 \%$ by reducing flowing bottom-hole pressure from 10.4 to $6.9 \mathrm{MPa}$ (1500 to $1000 \mathrm{psi}$ ). However, curtailing flowing bottom-hole pressure could exacerbate condensate dropout near the wellbore. 


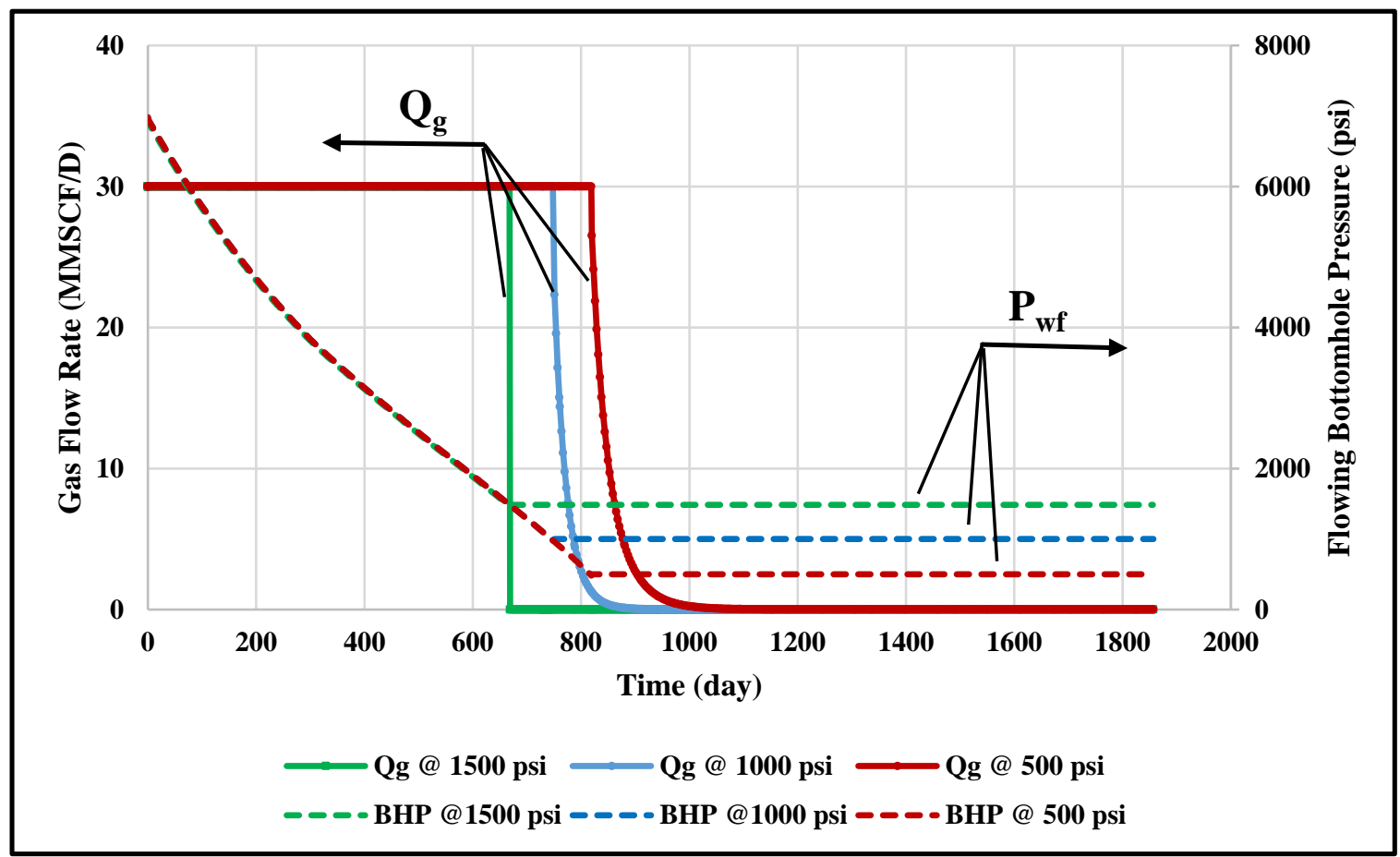

Figure 13. Profiles of gas-flow rates at different levels of flowing bottom-hole pressure.

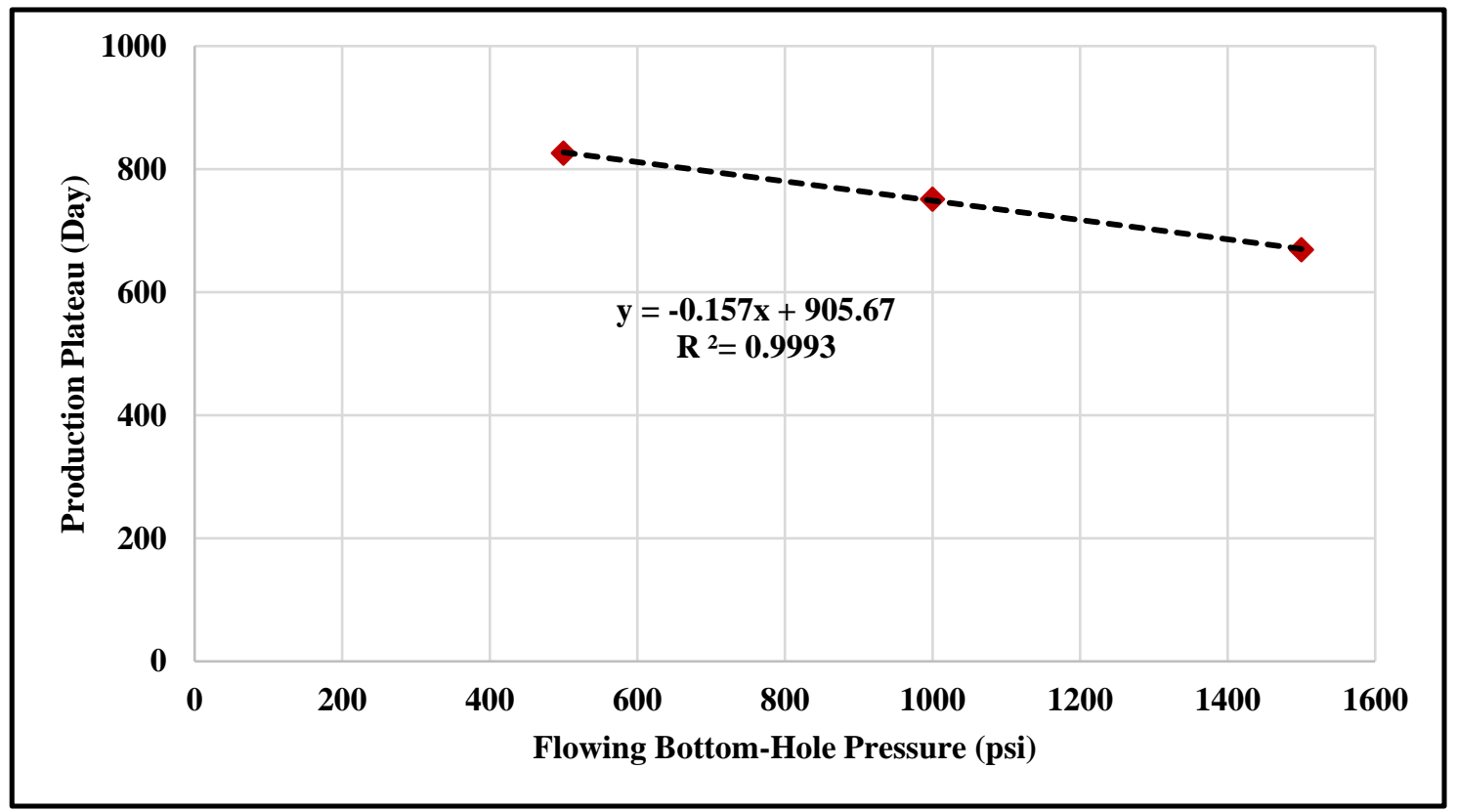

Figure 14. Duration of production plateau plotted against flowing bottom-hole pressure.

\subsection{Impact of Gas-Production Rate}

Figure 15 encapsulates gas-production profiles for gas-flow rates of 10, 30, and 60 MMSCFD, respectively. The corresponding flowing bottom-hole pressure profiles are plotted in Figure 16. It can be observed that a constant production rate of 60 MMSCFD could only be sustained for 400 days, with the rate sharply dropping thereafter due to flow impediments associated with condensate banking. Naturally, reducing gas-flow rate from 60 to 10 MMSCFD postpones the onset of liquid dropout. Plotting the duration of the production plateau maintained in days versus stabilized gas-flow rate suggested exponential relation, as indicated in Figure 17. 


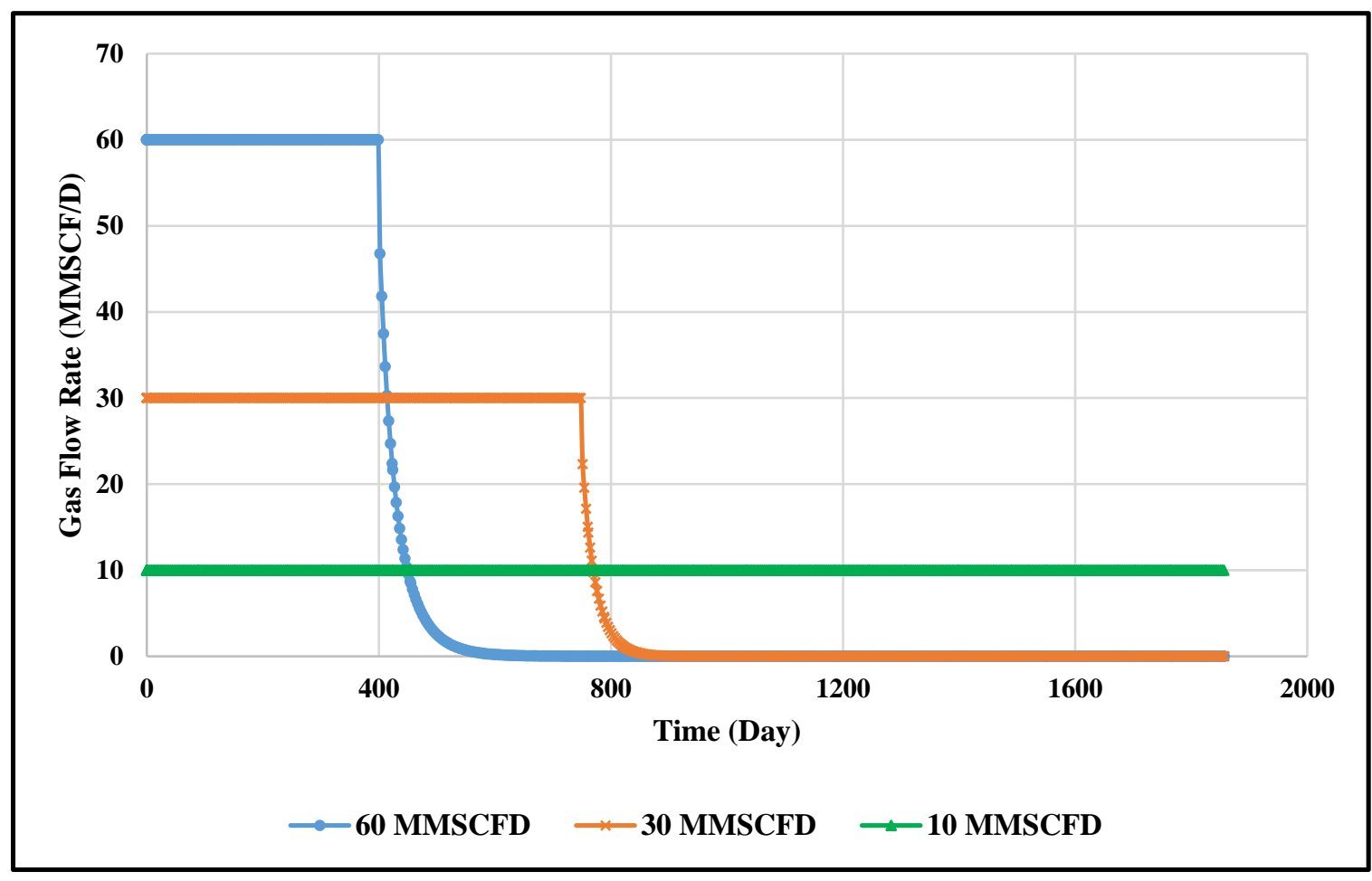

Figure 15. Profiles of gas production for various gas-flow rates.

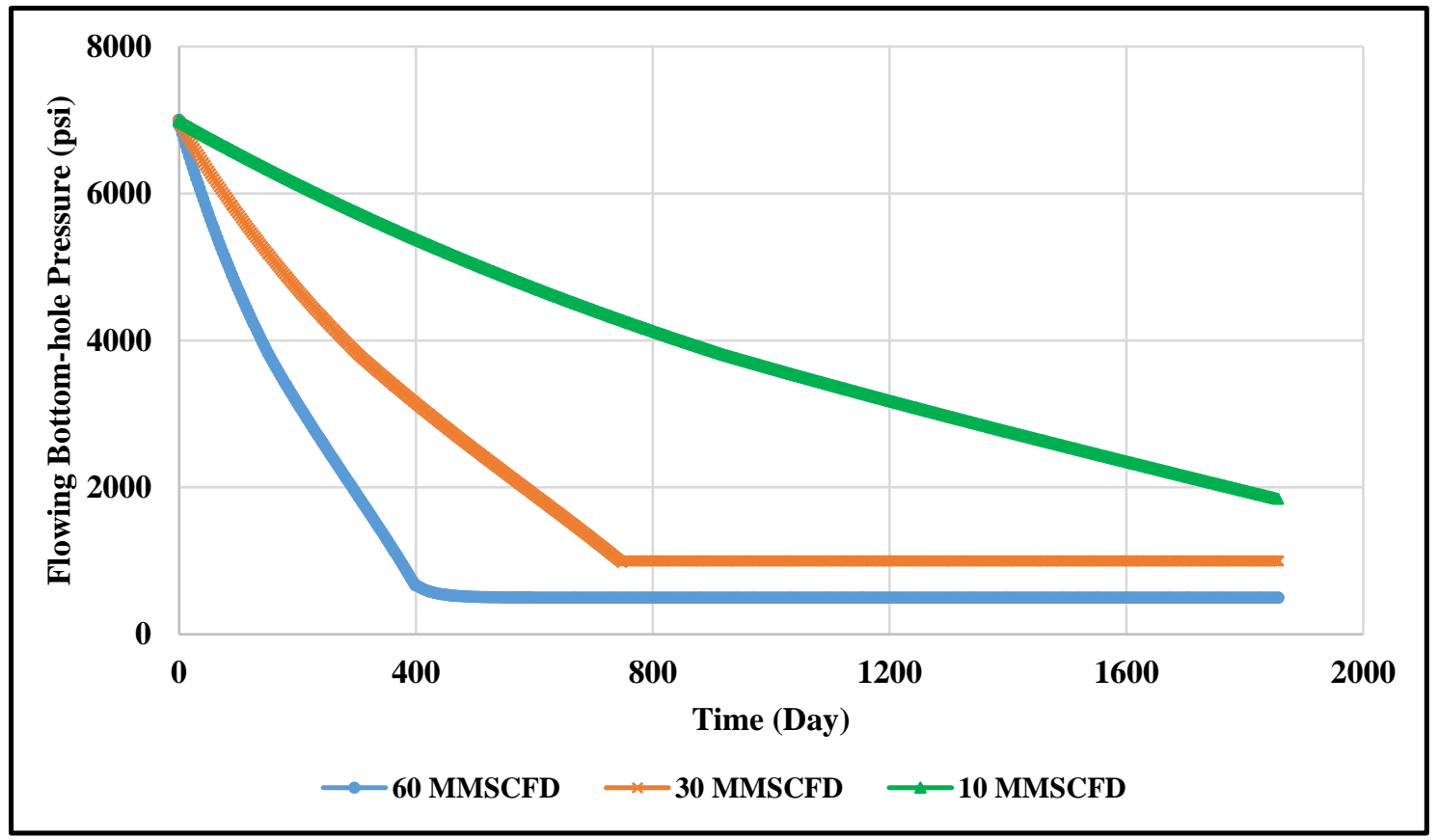

Figure 16. Profiles of flowing bottom-hole pressure at gas-production rates of 10, 30, and 60 MMSCFD, respectively. 


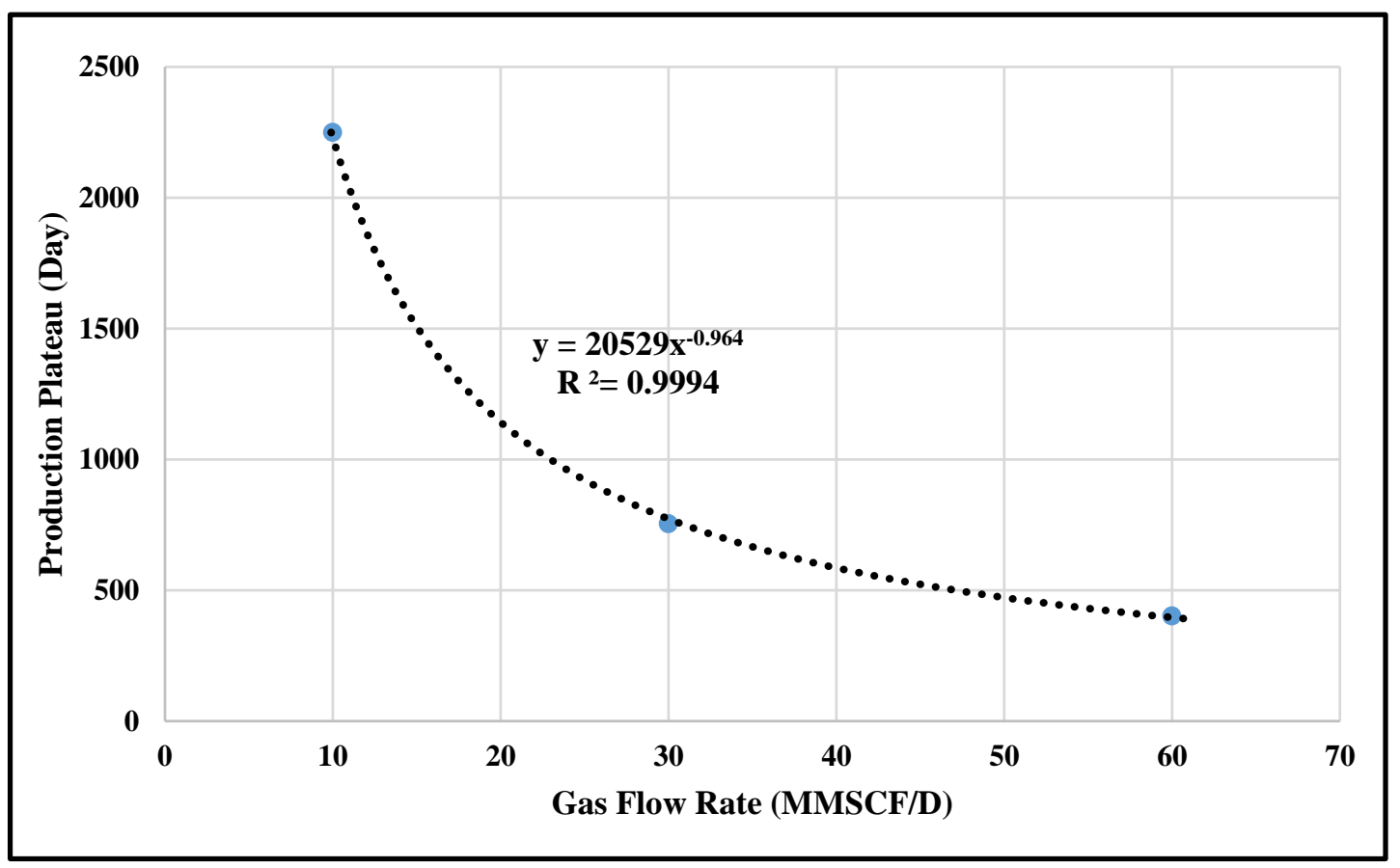

Figure 17. Stabilized production time (production plateau) plotted against gas-production rate.

\subsection{Thermochemical Treatment}

The overall impact on gas production upon injection of thermochemical fluids into a gas-condensate reservoir can be divided into three major components, all of which were included in the model. First, the reaction products, mainly steam and nitrogen, yield an increase in pressure of up to $34.5 \mathrm{MPa}$ (5000 psi) $[24,28,29]$. Thus, this effect finds equivalency in standard nitrogen injection. Second, the released heat, able to boost temperatures in the order of $422 \mathrm{~K}\left(300^{\circ} \mathrm{F}\right)$, promotes a reduction in viscosity [28]. Third, the pressure pulse resulting from released enthalpy stimulates the formation by creating microfractures. This particular effect was integrated by adjusting capillary pressure on the basis of the work of Hassan et al. [9,25], who reported a reduction of the former by around $51 \%$.

Figure 18 exemplifies the profiles of gas-flow rate and flowing bottom-hole pressure before and after thermochemical treatment. After 668 days of gas production, flowing bottom-hole pressure dramatically dropped, resulting in diminished gas-flow rate due to condensate development. At this point, gas production was halted, and chemical treatment commenced. In total, three treatment cycles were performed; a chemical concentration of 1 molar and total chemical volume of $1000 \mathrm{bbl}$ were utilized. Each cycle was initiated with the injection of the chemicals, followed by a one-week soaking period. After completion of the cycles, production continued applying a maximal gas-flow rate of $30 \mathrm{MMSCFD}$, and minimal flowing bottom-hole pressure of $10.4 \mathrm{MPa}$ (1500 psi). The intervention raised pressure and temperature in the near-wellbore region in excess of $31 \mathrm{MPa}(4500 \mathrm{psi})$ and $324.8 \mathrm{~K}$ $\left(125^{\circ} \mathrm{F}\right)$, respectively. Consequently, as illustrated in Figure 19, liquids were revaporized, allowing for 683 additional days of gas-flow rate at 30 MMSCFD, succeeding the remedial efforts (Figure 18). 


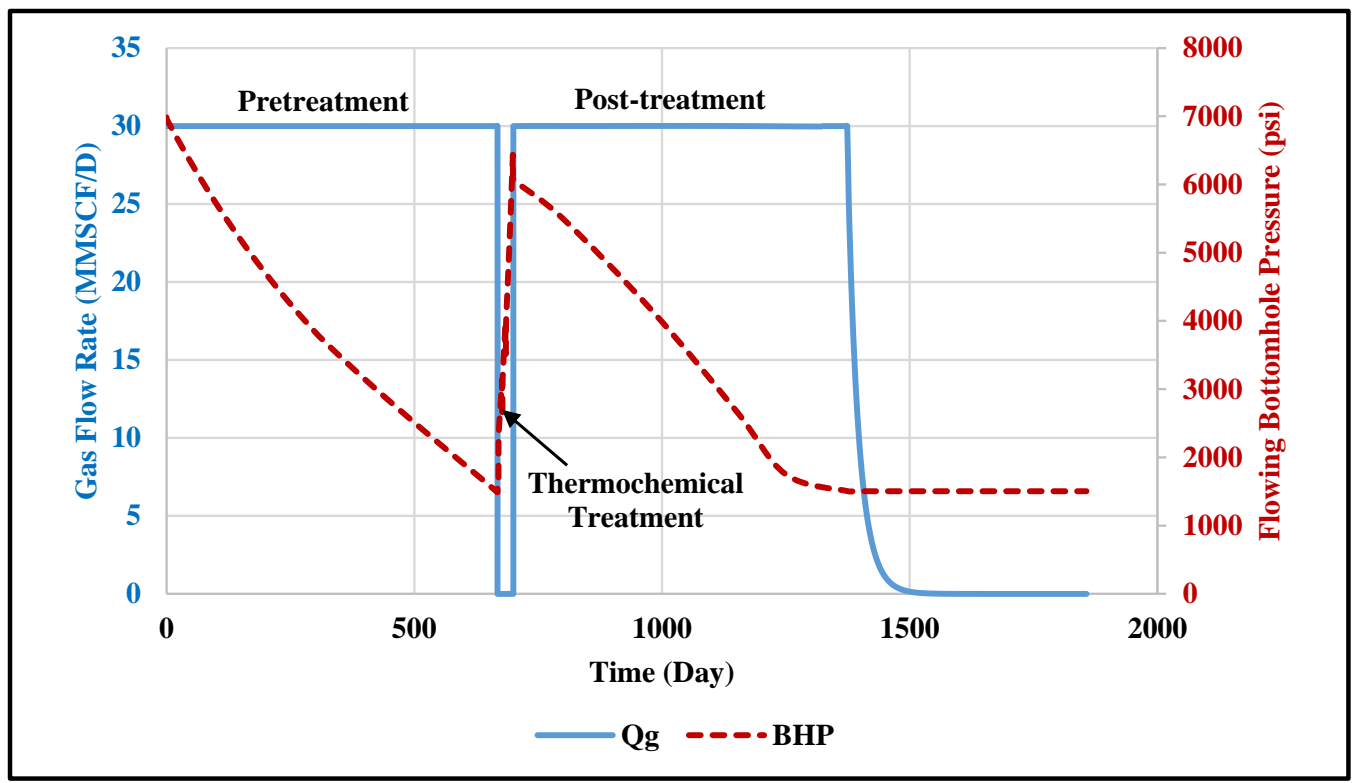

Figure 18. Profiles of gas-production rate and flowing bottom-hole pressure prior to and after thermochemical treatment.

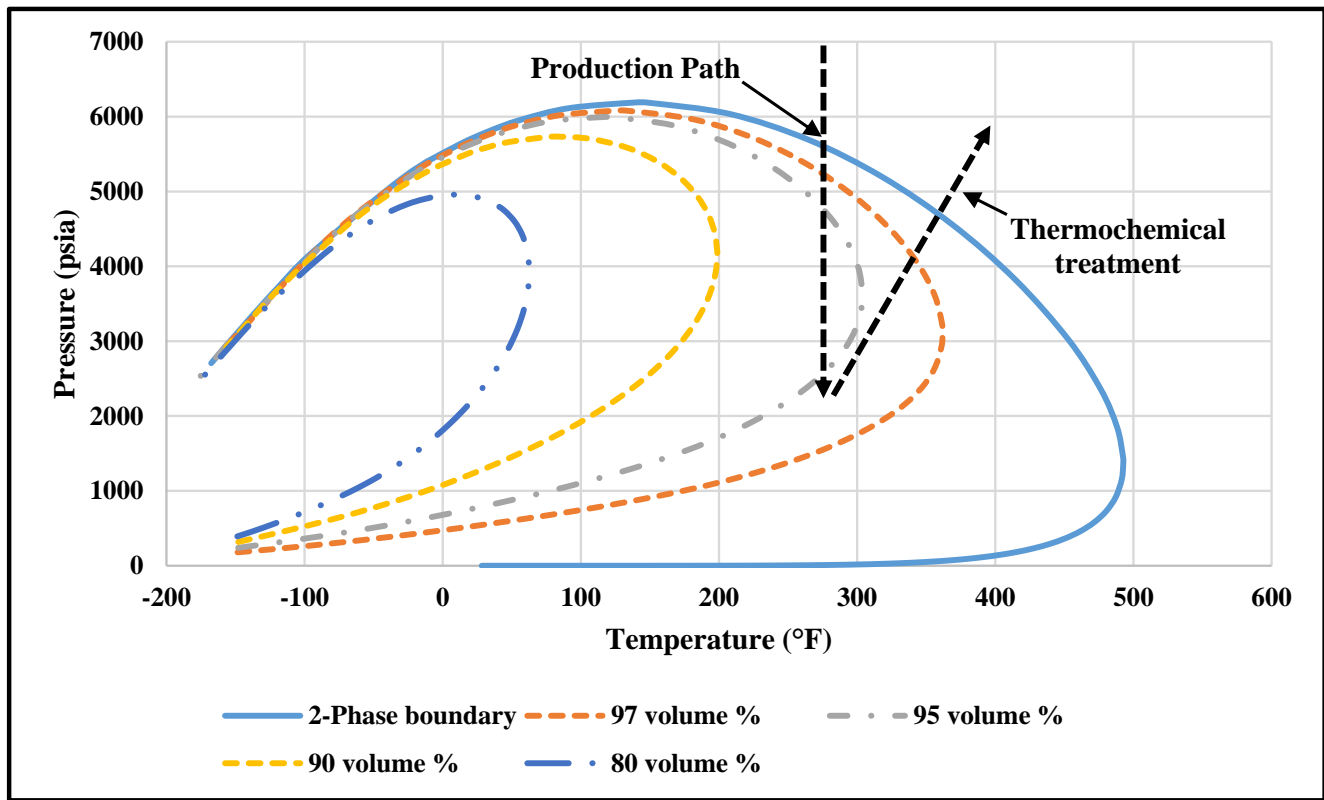

Figure 19. Revaporization of condensate liquid due to thermochemical treatment.

\subsection{Comparison Analysis}

The performance of the thermochemical treatment was compared to that of a conventional gas injection approach. The gas-injection process was simulated using reservoir and wellbore conditions similar to thermochemical injection. The production well was shut in after 668 days; subsequently, a mixture of $\mathrm{N}_{2}, \mathrm{CO}_{2}$, and $\mathrm{CH}_{4}$ gases was injected in three cycles for a total of one month. All other parameters were kept the same with respect to the thermochemical treatment. Figure 20 summarizes profiles for gas production and the corresponding flowing bottom-hole pressures pre- and post-treatment. After the gas-injection treatment, production was stable only for a period of 104 days (3.5 months). With reference to Figure 18, the thermochemical-based strategy enabled a sustained gas-production rate for a period of 683 days ( 22.7 months) for equal reservoir and well conditions, extending the production plateau by a factor of 6.5 compared to the gas-injection case. 


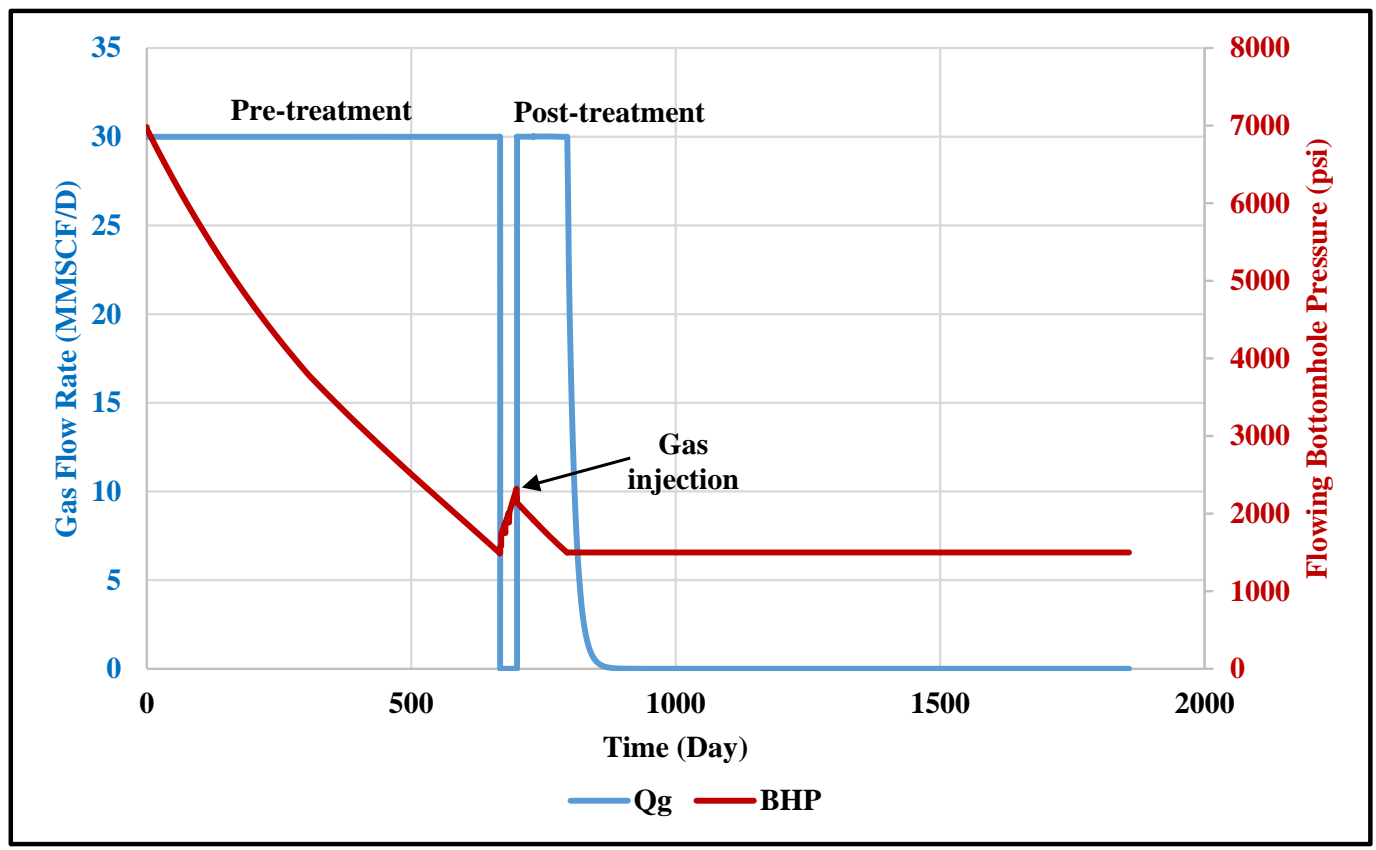

Figure 20. Profiles of gas production and associated flowing bottom-hole pressure before and after gas-injection treatment.

Cumulative gas production is plotted in Figure 21. The conventional approach only allowed for a production of 23.2 MMMSCF, equivalent to total gas recovery of about $25 \%$ of hydrocarbons in place. In contrast, the application of thermochemicals improved gas recovery by a factor of 1.76 to $40.8 \mathrm{MMMSCF}$, corresponding to a total recovery of about $89 \%$ of the gas in place. Given that the injected gas had a similar composition to that of reservoir fluids, no chemical reaction was expected, and only condensate revaporization took place. Gas injection only increases pressure in the near-wellbore region, fostering the revaporization of the condensate liquid, thereby improving gas flow into wellbore [16,17]. Thermochemical injection, however, not only increases pressure, but also reduces capillary forces and decreases condensate viscosity [24-27].

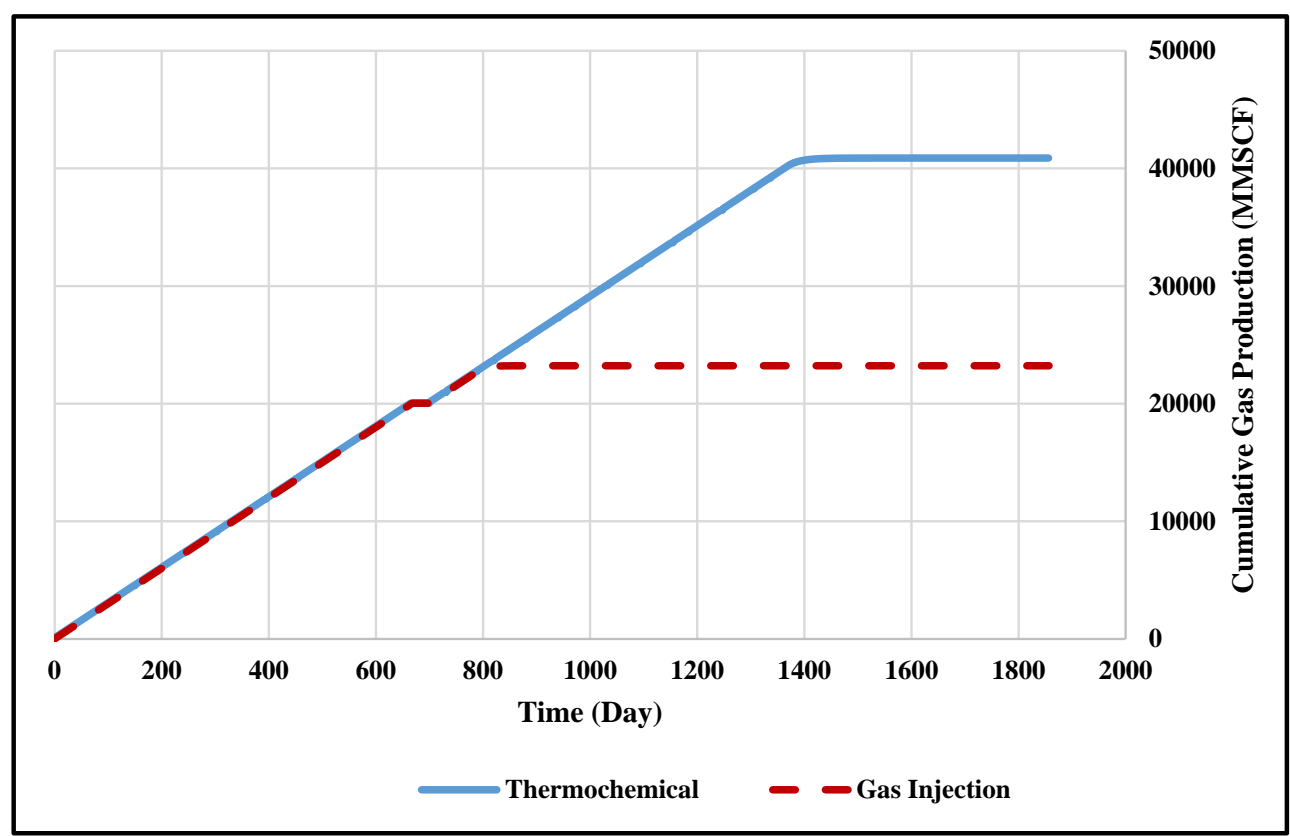

Figure 21. Profiles of cumulative gas production during thermochemical treatment and gas injection. 


\section{Conclusions}

This work presented a field-scale simulation quantifying the effectiveness of thermochemical injection for removing the condensate bank, thereby improving gas recovery. The following conclusions could be drawn from this work:

- Compared to conventional gas-injection treatment, the thermochemical approach was found to be vastly superior in coping with condensate-banking-related production issues.

- The simulation work indicated that thermochemical injection could restore the initial reservoir condition and sustain gas production for more than 680 days, compared to 104 days using gas-injection treatment.

- For the particular model used in this investigation, total gas recovery for the thermochemical-based procedure was $89 \%$, compared to $25 \%$ for the traditional gas-injection approach.

- In the case of the thermochemical-based approach, the exothermic nature of the thermochemical reaction released pressure and heat, thereby increasing pressure around the wellbore, and heating fluids in this region.

- Edicts reacted rather violently, giving rise to a pressure pulse, fostering the creation of microfractures accompanied by an according reduction in capillary pressure.

Author Contributions: Conceptualization, M.M., A.A.-M., and A.A.-N.; investigation, A.H. and M.A.; project administration, M.M. and A.A.-N.; supervision, M.M., A.A.-M., and A.A.-N.; validation, M.M., A.A.-M., and A.A.-N.; writing—original draft, A.H.; writing-review and editing, G.G. All authors have read and agreed to the published version of the manuscript.

Funding: This research was funded by Saudi Aramco under grant number CIPR2317.

Acknowledgments: The College of Petroleum and Geoscience at King Fahd University of Petroleum and Minerals, and Saudi Aramco are acknowledged for the support and permission to publish this work.

Conflicts of Interest: The authors declare no conflict of interest.

\section{References}

1. Craft, B.C.; Hawkins, M. Applied Petroleum Reservoir Engineering, Chapter-2 Gas-Condensate Reservoirs; Prentice-Hall: Englewood Cliffs, NJ, USA, 1959; pp. 59-96.

2. Al-Anazi, H.A.; Pope, G.A.; Sharma, M.M.; Metcalfe, R.S. Laboratory measurements of condensate blocking and treatment for both low and high permeability rocks. In Proceedings of the SPE Annual Technical Conference and Exhibition, SPE77546, San Antonio, TX, USA, 29 September-2 October 2002.

3. Sayed, M.A.; Al-Muntasheri, G.A. Mitigation of the effects of condensate banking: A critical review. SPE Prod. Oper. 2016, 31, 85-102. [CrossRef]

4. Muskat, M. Complete-Water-Drive Reservoirs, Chapter 11. Soc. Pet. Eng. 1949, 11, 528-644.

5. Kniazeff, V.J.; Naville, S.A. Two-phase flow of volatile hydrocarbons. Soc. Petrol. Eng. J. 1965, 5, 37-44. [CrossRef]

6. Novosad, Z. Composition and phase changes in testing and producing retrograde gas wells. SPE Res. Eng. 1996, 11, 231-235. [CrossRef]

7. Ahmed, T. Reservoir Engineering Handbook, Chapter-1: Fundamentals of Reservoir Fluid Behavior; Gulf Publishing Company: Houston, TX, USA, 2000; pp. 1-28.

8. Liu, D.; Sun, W.; Ren, D. Experimental Investigation of Pore Structure and Movable Fluid Traits in Tight Sandstone. Processes 2019, 7, 149. [CrossRef]

9. Hassan, A.; Mahmoud, M.; Al-Majed, A.; Alawi, M.B.; Elkatatny, S.; BaTaweel, M.; Al-Nakhli, A. Gas condensate treatment: A critical review of materials, methods, field applications, and new solutions. J. Pet. Sci. Eng. 2019, 177, 602-613. [CrossRef]

10. Linderman, J.T.; Al-Jenaibi, F.S.; Ghori, S.G. Feasibility study of substituting nitrogen for hydrocarbon in a gas recycle condensate reservoir. In Proceedings of the Abu Dhabi International Petroleum Exhibition and Conference, Abu Dhabi, UAE, 3-6 November 2008. 
11. Mahdiyar, H.; Jamiolahmady, M. Optimization of hydraulic fracture geometry in gas condensate reservoirs. Fuel 2014, 119, 27-37. [CrossRef]

12. Ayub, M.; Ramadan, M. Mitigation of near wellbore gas-condensate by $\mathrm{CO}_{2}$ huff-n-puff injection: A simulation study. J. Pet. Sci. Eng. 2019, 175, 998-1027. [CrossRef]

13. Luo, K.; Li, S.; Zheng, X.; Chen, G.; Dai, Z.; Liu, N. Experimental investigation into re-vaporization of retrograde condensate by lean gas injection. In Proceedings of the SPE Asia Pacific Oil and Gas Conference and Exhibition, Jakarta, Indonesia, 17-19 April 2001.

14. Millan Arcia, E.; Gerder, Y.; Gil, J. A novel improved condensate-recovery method by cyclic supercritical $\mathrm{CO}_{2}$ injection. In Proceedings of the SPE Latin American and Caribbean Petroleum Engineering Conference, Buenos Aires, Argentina, 15-18 April 2007.

15. Fevang, Ø.; Whitson, C.H. Modeling gas-condensate well deliverability. SPE Res. Eng. 1996, 11, $221-230$. [CrossRef]

16. Meng, X.; Sheng, J.J. Experimental and numerical study of huff-n-puff gas injection to re-vaporize liquid dropout in shale gas condensate reservoirs. J. Nat. Gas Sci. Eng. 2016, 35, 444-454. [CrossRef]

17. Meng, X.; Sheng, J.J. Optimization of huff-n-puff gas injection in a shale gas condensate reservoir. J. Uncon. Oil Gas Res. 2016, 16, 34-44. [CrossRef]

18. Wang, F.; Liu, Y.; Hu, C.; Wang, Y.; Shen, A.; Liang, S. Experimental study on feasibility of enhanced gas recovery through $\mathrm{CO}_{2}$ flooding in tight sandstone gas reservoirs. Processes 2018, 6, 214. [CrossRef]

19. Odi, U. Analysis and potential of $\mathrm{CO}_{2}$ huff-n-puff for near Wellbore condensate removal and enhanced gas recovery. In Proceedings of the SPE Annual Technical Conference and Exhibition, Society of Petroleum Engineers, San Antonio, TX, USA, 8-10 October 2012.

20. Monger, T.G.; Khakoo, A. The phase behavior of $\mathrm{CO}_{2}-\mathrm{Appalachian}$ oil systems. In Proceedings of the SPE Annual Technical Conference and Exhibition, San Antonio, TX, USA, 4-7 October 1981.

21. Jia, B.; Tsau, J.S.; Barati, R. A review of the current progress of $\mathrm{CO}_{2}$ injection EOR and carbon storage in shale oil reservoirs. Fuel 2019, 236, 404-427. [CrossRef]

22. Li, L.; Sheng, G.; Su, Y. Water-Gas Two-Phase Flow Behavior of Multi-Fractured Horizontal Wells in Shale Gas Reservoirs. Processes 2019, 7, 664. [CrossRef]

23. Khan, M.N.; Siddiqui, F.I.; Mansur, S.; Ali, S.D. Hydraulic fracturing in gas condensate reservoirs: Successes, setbacks and lessons learnt. In Proceedings of the SPE/PAPG Annual Technical Conference, Society of Petroleum Engineers, Islamabad, Pakistan, 10-11 November 2010.

24. Hassan, A.M.; Mahmoud, M.A.; Al-Majed, A.A.; Elkatatny, S.; Al-Nakhli, A.R.; Bataweel, M.A. Novel Technique to Eliminate Gas Condensation in Gas Condensate Reservoirs Using Thermochemical Fluids. Energy Fuels 2018, 32, 12843-12850. [CrossRef]

25. Hassan, A.M.; Mahmoud, M.A.; Al-Majed, A.A.; Al-Nakhli, A.R.; Bataweel, M.A.; Elkatatny, S. Mitigation of Condensate Banking Using Thermochemical Treatment: Experimental and Analytical Study. Energies 2019, 12, 800. [CrossRef]

26. Hassan, A.; Mahmoud, M.; Al-Majed, A.; Al-Shehri, D.; Al- Nakhli, A.; Bataweel, M. Gas Production from Gas Condensate Reservoirs Using Sustainable Environmentally Friendly Chemicals. Sustainability 2019, 11, 2838. [CrossRef]

27. Al-Nakhli, A.; Hassan, A.; Mahmoud, M.; Al-Majed, A. Removal of Condensate Banking from Different Formations Using Thermochemical Treatment. In Proceedings of the Abu Dhabi International Petroleum Exhibition \& Conference, Society of Petroleum Engineers, Abu Dhabi, UAE, 11-14 November 2019.

28. Al-Nakhli, A.R.; Sukkar, L.A.; Arukhe, J.; Mulhem, A.; Mohannad, A.; Ayub, M.; Arifin, M. In-Situ steam generation a new technology application for heavy oil production. In Proceedings of the SPE Heavy Oil Conference and Exhibition, Society of Petroleum Engineers, Kuwait City, Kuwait, 6-8 December 2016.

29. Alade, O.S.; Mahmoud, M.; Hassan, A.; Al-Shehri, D.; Al-Nakhli, A.; Bataweel, M. Evaluation of kinetics and energetics of thermochemical fluids for enhanced recovery of heavy oil and liquid condensate. Energy Fuels 2019, 33, 5538-5543. [CrossRef]

30. Hassan, A.; Mahmoud, M.; Al-Majed, A.; Al-Nakhli, A. New Chemical Treatment for Permanent Removal of Condensate Banking from Different Gas Reservoirs. ACS Omega 2019, 4, 22228-22236. [CrossRef]

31. Xu, H.; Fan, Y.; Hu, F.; Li, C.; Yu, J.; Liu, Z.; Wang, F. Characterization of pore throat size distribution in tight sandstones with nuclear magnetic resonance and high-pressure mercury intrusion. Energies 2019, 12, 1528. [CrossRef] 
32. Temeng, K.O.; Al-Sadeg, M.J.; Al-Mulhim, W.A. Compositional grading in the Ghawar Khuff reservoirs. In Proceedings of the SPE Annual Technical Conference and Exhibition, Society of Petroleum Engineers, New Orleans, LA, USA, 27-30 September 1998.

33. Kuntadi, A.R.I.F. North Field, Qatar: A Study of Condensate Blockage and Petroleum Streams Management. Master's Thesis, Norwegian University of Science and Technology (NTNU), Trondheim, Norway, June 2004.

34. Whitson, C.H.; Kuntadi, A. Khuff gas condensate development. In Proceedings of the International Petroleum Technology Conference (IPTC), Doha, Qatar, 21-23 November 2005.

35. Corey, A.T.; Rathjens, C.H.; Henderson, J.H.; Wyllie, M.R.J. Three-phase relative permeability. Trans. AIME 1956, 207, 349-351. [CrossRef]

(C) 2020 by the authors. Licensee MDPI, Basel, Switzerland. This article is an open access article distributed under the terms and conditions of the Creative Commons Attribution (CC BY) license (http://creativecommons.org/licenses/by/4.0/). 